\title{
Gating of Long-Term Potentiation (LTP) in the Thalamocortical Auditory System of Rats by Serotonergic (5-HT) Receptors
}

\section{Karen Ka Yan Lee}

A thesis submitted to the Department of Psychology

In conformity with the requirements for

the degree of Master of Science

Queen's University

Kingston, Ontario, Canada

(September, 2017)

Copyright @ Karen Ka Yan Lee, 2017 


\begin{abstract}
The neuromodulator serotonin (5-hydroxytryptamine, 5-HT) plays an important role in controlling the induction threshold and maintenance of long-term potentiation (LTP) in the visual cortex and hippocampus of rodents. Serotonergic fibers also innervate the rodent primary auditory cortex (A1), but the regulation of A1 plasticity by 5-HT receptors (5-HTRs) is largely uncharted. Thus, we examined the role of several, predominant 5-HT receptor classes (5$\mathrm{HT}_{1 \mathrm{~A}} \mathrm{Rs}, 5-\mathrm{HT}_{2} \mathrm{Rs}$, and 5-HT $\mathrm{H}_{3} \mathrm{Rs}$ ) in gating in vivo LTP induction at A1 synapses of adult, urethane-anesthetized rats. Theta-burst stimulation (TBS) applied to the medial geniculate nucleus resulted in successful LTP induction of field postsynaptic potential generated by excitation of thalamocortical and intracortical A1 synapses. Local application (by reverse microdialysis in A1) of the broad-acting 5-HTR antagonist methiothepin suppressed LTP at both thalamocortical and intracortical synapses, an effect that was mimicked by the selective $5-\mathrm{HT}_{2} \mathrm{R}$ antagonist ketanserin, but not the 5- $\mathrm{HT}_{1 \mathrm{~A}} \mathrm{R}$ blocker WAY 100635. Interestingly, antagonism of 5-HT 3 Rs by granisetron selectively blocked LTP at thalamocortical, but not intracortical A1 synapses. Further, in the absence of TBS delivery, granisetron application resulted in a pronounced increase in fPSP amplitude, suggesting that 5- $\mathrm{HT}_{3}$ Rs play an important role in regulating baseline (non-potentiated) transmission at A1 synapses. Together, these results indicate that activation of 5- $\mathrm{HT}_{2} \mathrm{Rs}$ and $5-\mathrm{HT}_{3} \mathrm{Rs}$, but not $5-\mathrm{HT}_{1 \mathrm{~A}} \mathrm{Rs}$, exerts a clear effect on LTP induction at A1 synapses, allowing 5-HT to act as a powerful regulator of long-term plasticity induction in the fully matured A1 of mammalian species.
\end{abstract}




\section{Acknowledgements}

To my life-coach, my mother Amy Pang, because I owe it all to you. Many thanks!

A million thanks to my supervisor, Dr. Hans Dringenberg. Words cannot describe how thankful I am for all the help and guidance you gave me. Without you I would not have been able to get to where I am today. I thank you from the bottom of my heart!

A very special gratitude goes to Dr. Cella Olmstead. It is an honor to have you on my committee. Thank you very much for your concern and all the effort you put into securing my future! I will do my best on this path that I have chosen.

I am grateful to all my committee members! My gratitude to Dr. Ken Rose and Dr. Richard Beninger for sharing your wisdom and sage advice. Thank you Dr. Jordan Poppenk and Dr. Mark Sabbagh for your insights and contributions to the thesis defense.

I would like to express my sincere gratitude to my professor, Dr. Janet Menard, for your continuous care, patience, and useful advice. Many thanks for being there in my time of need!

With a special mention to my friends, Chloe Soutar and Christina Ou. I cannot thank you enough for all your help. I truly appreciate the kindness and friendship that you have shown me. It was great sharing the laboratory with you during the last two years.

For my family, thank you for sticking with me through the best and the worst. I am thankful for every drop of blood, every bead of sweat, and every bitter tear you have shed for me. All the struggles and sacrifices you have made for me will fuel my motivation for striving towards a better future. I will do my best to make you proud.

Finally, I humbly thank my Heavenly Father for always being there for me and helping me every step of the way. Thank you for all these wonderful people you have brought into my life. I am truly blessed by Your love and everyone's kindness. Thank you! 


\section{Table of Contents}

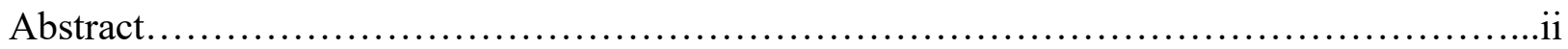

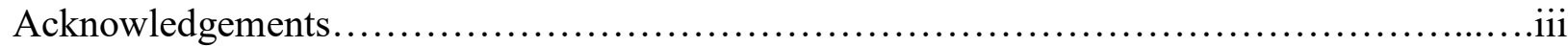

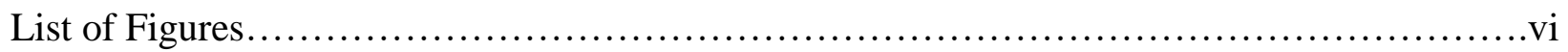

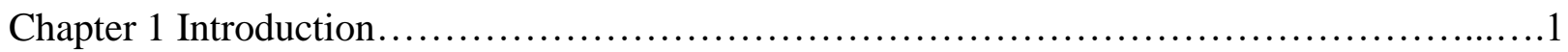

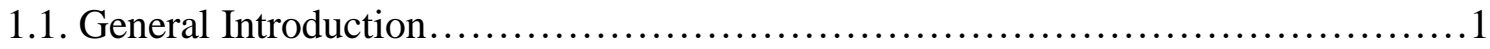

1.1.2. Synaptic plasticity: LTP and LTD ....................................

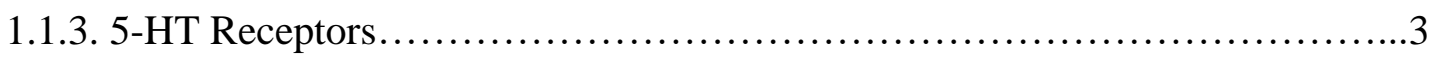

1.1.3.1. 5-HT1 Receptors.............................................. 4

1.1.3.2. 5-HT2A Receptors..............................................5

1.1.3.3. 5-HT3 Receptors................................................6

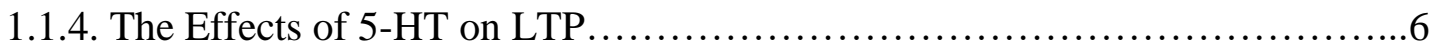

1.1.4.1. 5-HT Effects on Synaptic Plasticity in the Hippocampus.................6

1.1.4.2. 5-HT Effects on Synaptic Plasticity in the Prefrontal Cortex...............8

1.1.4.3. 5-HT Effects on Synaptic Plasticity in the Visual Cortex.................9

1.1.4.4. 5-HT Effects on Synaptic Plasticity in the Auditory Cortex...............10

1.1.5. Summary, Objectives, and Hypothesis of the Present Thesis.....................11

1.2. Gating of LTP in the Thalamocortical Auditory System of Rats by 5-HTRs ........14

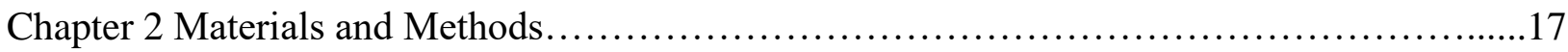

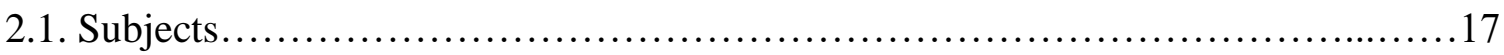

2.2. Surgical preparation............................................................

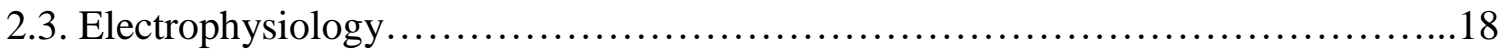

2.4. Drug application...............................................................

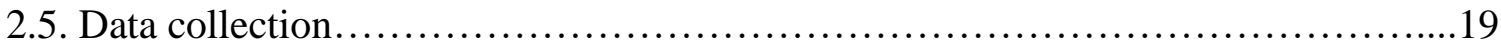

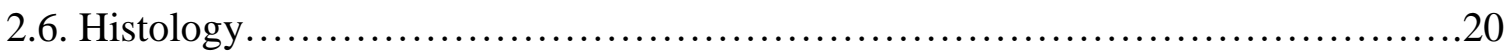

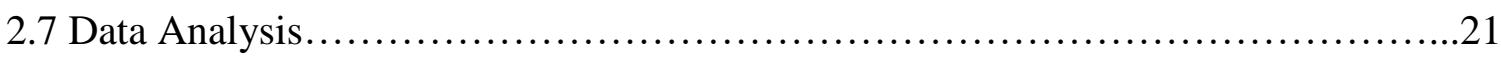

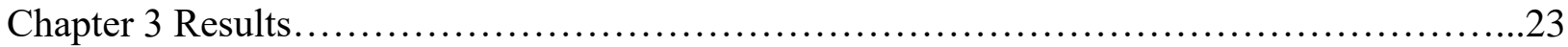

3.1 fPSP characteristics and LTP in during vehicle (aCSF/saline) application.............23 
3.2 Effects of 5-HTR antagonist application in A1 on LTP......................24

3.3 Effects of 5-HTR antagonist on baseline (pre-TBS) fPSP amplitude..............27

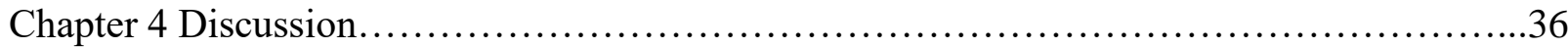

References.................................................................. 43 


\section{List of Figures}

Figure 1. Typical fPSPs recorded in A1 in response to ipsilateral MGN stimulation in the urethane-

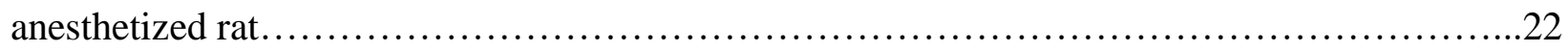

Figure 2. Effects of cortical application of methiothepin on LTP induction in A1 ...............29

Figure 3. Effects of cortical application of WAY 100635 on LTP induction in A1 ...............30

Figure 4. Effects of cortical application of ketanserin on LTP induction in A1 .................31

Figure 5. Effects of cortical application of granisetron on LTP induction in A1 ................32

Figure 6. Amplitude of fPSPs in all drug conditions prior to LTP induction....................33

Figure 7. Effects of cortical application of granisetron on fPSP amplitude in A1 ...............35 


\section{Chapter 1}

\section{Introduction}

\subsection{General Introduction}

Serotonin or 5-hydroxytryptamine $(5-\mathrm{HT})$ is a monoamine neurotransmitter found in the central nervous system (CNS), gastrointestinal tract, and blood platelets (Nichols \& Nichols, 2008). The 5-HT signaling molecule is widely distributed throughout the brain and innervates areas that mediate crucial brain functions, such as sensory processing, emotional regulation, and executive functioning. Further, this phylogenetically ancient neurotransmitter has the ability to reconfigure the neural circuitry of sensory and motor systems (Lesch \& Waider, 2012; Nichols \& Nichols, 2008; Ji \& Suga, 2007). More specifically, 5-HT plays an important role in modulating synaptic plasticity, development of axons and dendrites, synaptogenesis, neurogenesis, and cell migration in the CNS (Lesch \& Waider, 2012; Nichols \& Nichols, 2008; Ji \& Suga, 2007; Rao, 2012). As such, the serotonergic system and its receptors drive brain plasticity, which in turn can cause observable behavioral changes. Understanding how the serotonergic system influences neuroplasticity is essential for the understanding of normal and abnormal behaviors, in addition to the emerging concepts of treatment designs for the behavioral and psychological aspects of psychopathologies, ranging from Alzheimer's disease to drug addiction.

\subsubsection{Synaptic plasticity: LTP and LTD}

The extensive central 5-HT neurotransmitter system that is established for brain 5-HT neuronal signaling is known for its role in modulating cortical synaptic plasticity (Deneris, 2011). 5-HT projections originate from the median and dorsal raphe nuclei and innervate the entire forebrain via the dense network of 5-HT fibers (Lesch \& Waider, 2012; Deneris, 2011). Synaptic plasticity is the ability of neuronal circuits and connectivity to either strengthen or 
weaken over time. This capability allows the nervous system to adapt behavior, and to anticipate and control executive functions in accordance to the sensory information obtained from the changing environment (Feldman, 2009).

One form of synaptic plasticity is long-term potentiation (LTP), which refers to a longlasting increase in synaptic strength (Bliss and Lomo, 1973). LTP and long-term depression (LTD; i.e., a long-lasting decrease in synaptic coupling) are two of the probable mechanisms mediating experience-dependent plasticity of the cortex (Rao, 2012). The duration and magnitude of LTP are known to be influenced by various modulators, such as acetylcholine (ACh), 5-HT, noradrenaline, and others (Hasselmo, 1995).

LTP and LTD are forms of neuroplasticity that were first discovered in the hippocampus and later identified to be present at synapses throughout the forebrain, including the prefrontal, auditory, visual, and somatosensory cortices (Bennett, 2000; Malenka and Bear, 2004); both forms of plasticity have been identified as a probable mechanism that mediates CNS memory and learning processes (Lynch, 2004; Martin and Morris, 2002; Massey and Bashir, 2007; Neves et al., 2008). LTP can be defined as the process for the enhancement of synaptic efficacy that requires almost simultaneous activation of presynaptic activity (i.e., transmitter release) and postsynaptic depolarization that involves opening of both $\mathrm{N}$-methyl-D-aspartate receptors (NMDAR) and $\alpha$-amino-3-hydroxy-5-methyl-4-isoxazolepropionic acid receptors (AMPAR), along with the increase of intracellular calcium (Bliss \& Cooke, 2011; Meunier et al., 2017). The voltage dependent NMDAR is an ion channel protein and belongs to the general class of glutamate receptors (Bliss \& Cooke, 2011), while AMPAR act as rapid synaptic neurotransmission mediators in the CNS by acting as ionotropic transmembrane receptors for glutamate (Meunier et al., 2017). 
Typically, the induction of LTP is initiated by pre-synaptic glutamate release, causing the activation of post-synaptic AMPAR (Bliss \& Cooke, 2011; Meunier et al., 2017). Once the postsynaptic membrane is sufficiently depolarized, magnesium ions will be ejected from the NMDAR ion pore, allowing calcium and other cation to influx into the post-synaptic membrane (Bliss \& Cooke, 2011; Meunier et al., 2017). This influx results in the activation of several intracellular, calcium-dependent events, such as calmodulin-dependant protein kinase II (CaMKII), which causes AMPAR phosphorylation and/or AMPAR trafficking to the postsynaptic membrane (Bliss \& Cooke, 2011; Meunier et al., 2017).

Synaptic plasticity can be measured through field postsynaptic potentials (fPSPs). FPSPs are extracellular potential recordings of a population of cells (often pyramidal or granule cells in neocortical or hippocampal areas) following synaptic stimulation (Andersen et al., 2007; Lagerlund, 2002). The main advantage of this measurement is that fPSPs can provide detailed information on synaptic activity such as the amplitude, latency, and polarity of synaptic activity (Andersen et al., 2007; Lagerlund, 2002). There are two types of fPSPs: excitatory postsynaptic potentials (EPSP) are caused by inward, depolarizing current flow, that is, an inward (into the neuron) flow of positive ions, which results in negative, local extracellular potentials (Andersen et al., 2007; Lagerlund, 2002); inhibitory postsynaptic potentials (IPSP) are caused by a net outward, positive current flow, or a flow of negative ions into the cell, which results in positive local extracellular potentials (Andersen et al., 2007; Lagerlund, 2002).

\subsubsection{5-HT Receptors}

As mentioned, while the initiation of LTP typically involves glutamatergic signalling, neuromodulators such as 5-HT can influence the induction threshold, magnitude, and duration of 
LTP. The effects of 5-HT in regulating behaviour, cognition, neuronal activity, and synaptic plasticity are mediated by a number of distinct 5-HT receptors (5-HTRs) that are linked to different signal mechanisms and ion channels (Deneris, 2011; Nichols \& Nichols, 2008). 5-HT neuromodulation in rats originates in about 26000 serotonergic neurons, along with 14 5-HT postsynaptic and/or presynaptic receptor subtypes (Deneris, 2011; Basura et al., 2008; Nichols \& Nichols, 2008); of these 14 subtypes, the 5-HT1Rs, 5-HT2Rs and 5-HT3Rs subtypes are those that have been studied in most detail.

\subsubsection{5-HT1 Receptors}

Binding of 5-HT to the 5-HT1R decreases cellular excitability of 5-HT-containing neurons and mediates hyperpolarization of cells in the prefrontal and entorhinal cortices (Araneda et al., 1991; Beique et al., 2004; Grunschlag et al., 1997; Nichols \& Nichols, 2008). Neuronal membrane hyperpolarization is the most common function of this Gai coupled receptor, which leads to the suppression of neuronal firing (Nichols \& Nichols, 2008). G protein coupled receptors span the intracellular and extracellular domains through seven transmembrane spanning helices (Nichols \& Nichols, 2008). The 5-HT1R is expressed both presynaptically and postsynaptically throughout the brain and can negatively couple to the adenylyl cyclase second messenger system to inhibit cAMP formation (Basura et al., 2008; Sodhi \& Sanders-Bush, 2004, Nichols \& Nichols, 2008). The 5-HT1R family can be divided into the following subtypes: 5HT1A, 5-HT1B, 5-HT1D, 5-HT1E, and 5-HT1F (Nichols \& Nichols, 2008). 5-HT1ARs are also located on neurons in the raphe nuclei, where they act as somatodendritic autoreceptors (Nichols \& Nichols, 2008). Out of all the 5-HTR subtypes, the structure of the 5-HT1AR is most similar 
to adrenergic receptors, which leads 5-HT1ARs to have a relatively high binding affinity for adrenoceptor agents (Nichols \& Nichols, 2008).

\subsubsection{5-HT2A Receptors}

The 5-HT2AR has a major role in neuronal development, cell migration, and neuronal activity regulation, especially in the prefrontal cortex (Guiard \& Giovanni, 2015). 5-HT2AR is a type of Gaq coupled receptor (Nichols \& Nichols, 2008), which has two main mechanisms of action. The first mechanism is a cascade that begins with the hydrolysis of the membrane phosphoinositides, followed by subsequent formation of the signaling molecules, inositol phosphates and diacyl glycerol (Nichols \& Nichols, 2008), activation of protein kinase C and, finally an elevation of intracellular calcium (Nichols \& Nichols, 2008). The second mechanism starts with the activation of the Rho signaling pathway, leading to the production of focal

adhesion molecules and fibers that regulate structural changes inside the cell (Nichols \& Nichols, 2008).

In the human brain, levels of 5-HT2AR are heterogeneously distributed, with particularly high 5-HT2AR densities distributed in cortical layers III and V (Nichols \& Nichols, 2008). These cortical areas include the frontal cortex, parietal cortex, temporal cortex, occipital cortex, and entorhinal area (Nichols \& Nichols, 2008). 5-HT2ARs have been associated with many physiological functions such as sleep, memory, nociception, reward behaviors, and neuropsychiatric disorders such as depression (Guiard \& Giovanni, 2015), depending on the particular location of these receptors. 


\subsubsection{5-HT3 Receptors}

5-HT3Rs are ligand-gated cation channels and mediate rapid synaptic brain transmissions (Sodhi \& Sander-Bush, 2004; Walstab, Rappold \& Niesler, 2010; Lummis, 2004). Structurally, 5-HT3R have a cation permeable water filled pore surrounded with five subunits (Walstab, Rappold \& Niesler, 2010; Lummis, 2004). The permeable ions include calcium, sodium, and potassium (Walstab, Rappold \& Niesler, 2010; Lummis, 2004). 5-HT3R are also part of the Cysloop family, which includes $\gamma$-aminobutyric acid (GABA) A, nicotinic acetylcholine receptors, glycine receptors and Zinc activated cation channel (Walstab, Rappold \& Niesler, 2010; Lummis, 2004). Together, accumulating evidence indicates that 5-HT3R can function as modulators not only of 5-HT release, but also the release of GABA, dopamine, and acetylcholine (Farber et al., 2004; Walstab, Rappold \& Niesler, 2010).

\subsubsection{The Effects of 5-HT on LTP}

The role of 5-HT in synaptic plasticity has been assessed with various methods, mostly in the hippocampus, amygdala, and the visual cortex, as well as a few investigations in the prefrontal cortex and auditory cortex (Cynader et al., 1980; Persico et al., 2001; Basura et al., 2008). The various methods used to manipulate 5-HT activity include the pharmacological depletion of serotonin or the serotonin precursor, tryptophan; creating serotonergic circuit lesions; and the blockade of specific types of serotonergic receptors.

\subsubsection{5-HT Effects on Synaptic Plasticity in the Hippocampus}

Hippocampal 5-HT innervation originates in the raphe (the dorsal and median raphe) nuclei of the brainstem (Wyss et al., 1979). 5-HT neurons form nine nuclei clusters along the 
rostrocaudal axis and can be divided into three sections, the dorsal raphe nuclei, the median raphe nuclei and the caudal linear nucleus (Dahlstrom \& Fuxe; 1964). The rostral section mostly projects to the forebrain and innervates the hippocampus (Gulyás et al., 1999).

Investigations in the hippocampus have found that 5-HT can influence the induction of LTP. 5-HT application to the hippocampus has been shown to activate 5-HT receptors and inhibit LTP induction (Villani \& Johnston, 1993; Corradetti et al., 1992). This LTP inhibition can be partially blocked and LTP can be facilitated by 5-HT antagonists that block 5-HT1, 5HT2, or 5-HT3 receptors (Villani \& Johnston, 1993; Reznic \& Staubli, 1997; Corradetti et al., 1992; Passani et al., 1994).

The 5-HT1ARs, which are localized in high density on granular and pyramidal cells, are known to hyperpolarize hippocampal cells (Burnet et al., 1995). By using 5-HT1AR agonists, Normann and colleagues (2000) demonstrated that 5-HT1AR agonists impair hippocampal plasticity (LTD) induction. Further, Kojima and colleagues (2003) suggested that 5-HT1ARs may be responsible for the inhibition of LTP in CA1 seen following administration of a selective serotonin reuptake inhibitor (SSRI). As for 5-HT2ARs, its agonists have been shown to facilitate LTP in the hippocampus (Wang \& Arvanov, 1998). 5-HT3Rs are located in high densities on interneurons in the hippocampus (Morales et al., 1996; Piguet \& Galvan, 1994). Hippocampal 5HT3Rs have been associated with the stimulation of GABA release, leading to membrane hyperpolarization of hippocampal neurons (Morales et al., 1996; Piguet \& Galvan, 1994). Staubli and $\mathrm{Xu}$ (1995) applied 5-HT3R antagonists onto the hippocampus and discovered that this facilitated LTP, which indicates that activation of 5-HT3Rs exerts an inhibiting effect on hippocampal LTP inductions; this conclusion is consistent with data by Ohashi et al. (2003), showing that 5-HT acts to limit LTP induction in the hippocampus. 


\subsubsection{5-HT Effects on Synaptic Plasticity in the Prefrontal Cortex}

A dysfunction or downregulation of post-synaptic 5-HT1AR in the PFC has been associated with anxiety disorders, depression, as well as fear disorders and psychosis (Lanzenberg et al., 2007).

Although the specific functions of 5-HT1ARs in the PFC are still not well understood, it is known that they regulate the excitability of glutamatergic and GABAergic neurons, either on the neuronal targets of 5-HT neurons, as heteroreceptors, or on the serotonergic neurons themselves as autoreceptors, where they exert negative feedback over the release of 5-HT (Puig \& Gulledge, 2011). Between 50-60\% of post-synaptic 5-HT1AR are expressed in glutamatergic neurons, while $25 \%$ are expressed in GABAergic interneurons, which then innervate pyramidal cells in the PFC (Santana et al., 2004).

Recently, Meunier and colleagues (2017) have proposed an intriguing model of how 5HT1AR may modulate LTP in the PFC. Like other forms of LTP (e.g., in the hippocampus), LTP and LTD in the PFC are thought to involve NMDAR and the subsequent externalization (for LTP) or internalization (for LTD) of AMPA receptors, depending on the magnitude of calcium signalling in the postsynaptic cell (Meunier et al., 2017).

Meunier and colleagues (2017) conducted multiple experiments by decomposing synaptic conductance into its excitatory and inhibitory components. First, Meunier and colleagues (2013) showed that the activation of 5-HT1AR increased the evoked NMDA currents, which indicates a 5-HT1A receptor-induced modulation of NMDA receptors. Subsequently, Meunier and colleagues (2017) experimented on the layer V pyramidal neurons of 5-HT1AR knock-out mice and found that excitatory synapse transmission is modulated by the presence of 5-HT1AR. Further, 5-HT1ARs are necessary for the activation of glycogen synthase kinase $3 \beta$ (GSK3 $\beta$ ), 
which shifts the excitation-inhibition balance of synaptic plasticity towards favoring LTD over LTP induction (Meunier et al., 2015; Meunier et al., 2017).

\subsubsection{5-HT Effects on Synaptic Plasticity in the Visual Cortex}

There are many studies that have examined the role of 5-HT in the gating of plasticity at V1 synapses. Several studies have found that 5-HT impairs plasticity in V1 by blocking or inhibiting LTP induction. Levels of 5-HT in V1 show a pronounced increase over the course of postnatal development, resulting in the activation of 5-HT1 and 5-HT2 receptors, both of which have been shown to inhibit LTP induction (Kim et al., 2006; Gagolewicz \& Dringenberg, 2016). In particular, perhaps the only in vivo experiment of the influence of 5-HT LTP in V1 has shown an age-dependent switch in the role of 5-HT1AR in gating V1 plasticity, suggesting that 5HT1ARs facilitate LTP in the juvenile brain, but switch to an inhibitory function in the fully matured V1 (Gagolewicz \& Dringenberg, 2016); as mentioned, a similar effect of 5-HT to inhibit LTP has also been shown in the hippocampal formation of rodents.

In contrast, other studies have suggested that 5-HT facilitates LTP induction in the visual cortex (Kojic et al., 1997; Kojic et al., 2000; Park et al., 2012) with 5-HT2 receptor being the major LTP facilitator in layer 4 of the primary visual cortex (Kojic et al., 2001). Other studies have suggested that the facilitation of LTP induction is caused by presynaptic 5-HT2 receptors (Rozas et al., 2012) that activate protein kinase $\mathrm{C}$ and subsequently elevate intracellular calcium (Nichols \& Nichols, 2008).

Together, a brief review of the literature suggests that the precise role of 5-HT in LTP modulation in the visual cortex is still not well understood. Factors such as investigating LTP under in vivo vs. in vitro conditions, or the use of rodents of different ages and developmental 
status may account for some of the discrepancies in the experimental results. However, it is clear that further studies are required to develop a more complete understanding of the functions of 5HT in the gating of cortical plasticity, including V1.

\subsubsection{5-HT Effects on Synaptic Plasticity in the Auditory Cortex}

To date, the role of 5-HT as a regulator of plasticity induction in the primary auditory cortex (A1) has not received a lot of attention. Several studies have assessed the functional consequences of alterations in 5-HT transmission (e.g., 5-HT/tryptophan depletions) on activity in A1 (Ahveninen et al., 2003; Kahkonen et al., 2002a; Kahkonen et al., 2002b; Del Angel-Meza et al., 2002; Hegerl \& Juckel, 1993). These studies found evidence to support the notion that 5HT regulates the processing of auditory stimulus intensity (Kahkonen et al., 2002b; Hegerl \& Juckel, 1993) and may also play a role in regulating gender-specific stimulus processing by A1 neurons (Ahveninen et al., 2003; Kahkonen et al., 2002a).

Evidence for a more direct role of 5-HT and its receptors in auditory cortical plasticity was provided by Ji and Suga (2007), who examined tone-induced responses and receptive field plasticity in A1 neurons of bats. Earlier work had shown that exogenous 5-HT application can enhance GABAergic activity and reduce auditory-evoked responses in neurons of the inferior colliculus, the channel for the majority of auditory signals (Hurley et al., 2002). Ji and Suga (2007) extended this work by assessing if 5-HT modulates plasticity directly in A1, and by examining the receptor mechanisms that mediate effects of 5-HT in A1. Using an auditory fear condition paradigm, the bats were exposed to a conditioned tonal stimulus (CS; train of tone bursts) paired with the unconditioned stimulus (US; electric foot shock) applied every $30 \mathrm{~s}$ for either a 15 (weak stressed condition) or a 30 (strongly stressed condition) minute conditioning 
period. Ji and Suga (2007) found that 5-HT application to A1 is effective in modulating conditioning-induced plasticity (increased neuronal responses to the CS) in A1 neurons. Interestingly, the precise functions of 5-HT changed with the level of stress experienced by the animal, in that 5-HT facilitated A1 plasticity in the mildly stressful condition, but exerted a suppressant effect on plasticity in the strongly stressful condition.

Lastly, the effects of 5-HT on LTP in A1 have been investigated through studies using treatment with a selective serotonin reuptake inhibitor (SSRI). Dringenberg et al. (2014) assessed the effects of chronic (for 2 weeks) treatment with the SSRI fluoxetine on thalamocortical (medial geniculate nucleus to A1) LTP in adult rats. The results showed that fluoxetine treatment suppressed LTP in A1, suggesting that chronic SSRI treatment may inhibit plasticity induction in the neocortex of adult rodents (Dringenberg et al., 2014). At present, it is not known whether this effect involves the serotonergic system, or whether it is mediated by other effects that result from chronic SSRI exposure.

\subsubsection{Summary, Objectives, and Hypothesis of the Present Thesis}

The summary provided above indicates that 5-HT can influence the induction of plasticity in many areas of the mammalian forebrain (e.g., hippocampus, amygdala, neocortex). The experiments contained in this thesis were designed to further clarify the role of 5-HT in the gating of plasticity induction in the mammalian A1. Specifically, I examined the specific roles of 5-HT1Rs, 5-HT2Rs, and 5-HT3Rs in the induction of thalamocortical LTP between the medial geniculate nucleus (MGN) and A1 of adult rats.

Prior work has demonstrated that serotonin acts to modulate plasticity in the rodent cortex. For the visual cortex, several lines of evidence indicate that 5-HT exerts an inhibitory 
effect on LTP induction. In fact, the only in vivo study of the primary visual cortex concluded that 5-HT1AR activation exerts an inhibitory role on LTP in adult rats; results from the in vitro studies are somewhat contradictory, with different papers reporting facilitating and inhibitory effects on LTP induction following 5-HT receptor stimulation. Since both the primary visual cortex and the primary auditory cortex are neocortical brain regions and primary sensory areas that receive sensory information from primary nerve projections, 5-HT may exert similar effects on LTP in both of these cortical regions. Consequently, I hypothesize that 5-HT will inhibit LTP induction in A1 of adult rats. This inhibitory effect will be removed by blockade of 5-HT receptors, resulting in a facilitation of LTP. 


\section{Gating of Long-Term Potentiation (LTP) in the Thalamocortical Auditory System of Rats by Serotonergic (5-HT) Receptors}

Karen K.Y. Lee and Hans C. Dringenberg

(Submitted manuscript) 


\subsection{Gating of LTP in the Thalamocortical Auditory System of Rats by 5-HTRs}

Synaptic plasticity, or the ability of neuronal connectivity to change over time, plays a crucial role in the ability of the nervous system to adjust responses to incoming sensory stimuli and store information for prolonged time periods (Bliss and Collingridge, 1993; Hebb, 2002; Martin and Morris, 2002). Two widely studied forms of synaptic plasticity are long-term potentiation (LTP) and long-term-depression (LTD), which refer to long-lasting increases and decreases, respectively, of synaptic strength (Bennett, 2000; Malenka and Bear 2004). The interest in LTP and LTD stems, at least in part, from considerable evidence that the synaptic and molecular mechanisms mediating LTP and LTD are similar or identical to those recruited during training and memory formation, indicating that LTP and LTD constitute important mechanism for behavioral plasticity in various animal species (Lynch, 2004; Martin and Morris, 2002; Massey and Bashir, 2007; Neves et al. 2008).

LTP and LTD are readily induced at synapses throughout the forebrain, including the hippocampal formation, amygdala, striatum, and neocortex (Bennett, 2000; Malenka and Bear, 2004; Tsumoto, 1992). An important aspect of LTP is that the induction threshold, magnitude, and duration of synaptic potentiation are strongly influenced by the chemical milieu, particularly the levels of various neuromodulators such as acetylcholine (ACh), noradrenaline (NA), histamine, or serotonin (5-hydroxytryptamine, 5-HT; Dringenberg and Kuo, 2006; Gu, 2002; Kojic et al., 1997). Given that their release shows systematic changes over the sleep-wake cycle (Scammell et al. 2017), fluctuating levels of ACh, 5-HT, NA, and others likely play an important role in mediating the influence of waking and sleep states on the induction/encoding, consolidation, and elimination of synaptic plasticity and memory traces in neuronal circuits (Power, 2004). 
The role of neocortical 5-HT release in gating plasticity induction and maintenance has been extensively studied in the visual cortex (V1) of rodents. In slices obtained from kittens or adult rats, bath application of 5-HT can result in a pronounced facilitation of LTP at V1 synapses (Kojic et al., 1997, 2000; Park et al., 2012), while 5-HT depletions have been shown to impair LTP induction, an effect that is mimicked by 5-HT receptor (5-HTR) antagonists acting at either 5-HT ${ }_{1 \mathrm{~A}} \mathrm{Rs}$ or $\mathrm{HT}_{2} \mathrm{Rs}$ (Inaba et al., 2009). Even though these data suggest that 5-HT exerts a facilitating effect on LTP, there is also evidence that 5-HT can inhibit LTP induction in V1, thereby contributing to the stability of sensory networks (Edagawa et al., 1998, 2000; Gagolewicz and Dringenberg, 2016; Kim et al., 2006). The apparent discrepancy of these experimental results may be due to the differences in age and developmental status of these animals, since recent data suggest that 5-HT acts to facilitate and inhibit plasticity in juveniles and adult animals, respectively (Gagolewicz and Dringenberg, 2016).

Similar to V1, the temporal cortex of mammals, including the primary auditory cortex (A1), is densely innervated by 5 -HT fibers originating mainly in the dorsal raphe nucleus (Campbell et al., 1987; Harding et al., 2004; Törk, 1990), and the major classes of 5-HTRs are expressed throughout the temporal/A1 cortex (Barnes and Sharp, 1999; Basura et al., 2008; Clemett et al., 2000; Cornea-Hebert et al., 1999; Garcia-Oscos et al., 2015; Kilpatrick et al., 1987; Leysen et al., 1982; Malgouris et al., 1993). Studies in bats subjected to an auditory fear conditioning paradigm have shown that 5-HT and 5-HTRs exert potent, gating functions over receptive plasticity induction in A1 (Ji and Suga, 2007). Further, 5- $\mathrm{HT}_{2 \mathrm{~A}}$ receptors facilitate NMDA receptor (NMDAR)-dependent synaptic potentiation at thalamocortical synapses between the mediodorsal thalamus and prefrontal cortex in mice (Barre et al., 2016). 
The thalamocortical auditory system between the medial geniculate nucleus (MGN) and A1 of rodents readily expresses NMDAR-dependent LTP in both juvenile and adult animals (Hogsden 2009a,b; Soutar et al., 2016; Speechley et al., 2007). LTP in this system has been suggested to mediate receptive field plasticity and other learning-related adjustments in synaptic connectivity following auditory experiences (Tzounopoulos and Leão, 2012). To the best of our knowledge, the role of different 5-HTRs on LTP in this system has not been addressed. Thus, we examined the effects of blockade of several classes of 5-HTRs (5-HT ${ }_{1 \mathrm{~A}} \mathrm{Rs}, 5-\mathrm{HT}_{2} \mathrm{Rs}$, and 5$\mathrm{HT}_{3} \mathrm{Rs}$ ) on the induction of LTP at thalamocortical and intracortical synapses in A1 of adult rats in vivo. 


\section{Chapter 2}

\section{Materials and Methods}

\subsection{Subjects}

The experiments were conducted on adult, male Long-Evans male rats (about 250-450 g; obtained from Chares River Laboratories Inc., Saint-Constant, Quebec, Canada). Each rat was used for one experiment only. Animals were group housed (maximally 4 rats/cage) in standard plastic cages $(51 \times 40 \times 21 \mathrm{~cm})$ under a 12:12 reversed light cycle (lights on at 19:00h). Room temperature was kept at $21 \pm 2^{\circ} \mathrm{C}$ and each cage had food and water available ad libitum. All efforts are made to minimize animal suffering and the number of rats employed for all experiments. All experimental procedures were in compliance with the regulations set by the Canadian Council Animal Care Committee and approved by the Queen's University Animal Care Committee.

\subsection{Surgical preparation}

Rats were deeply anesthetized by means of urethane (Sigma-Aldrich, Oakvile, ON., Canada) administration (total dose of $1.5 \mathrm{~g} / \mathrm{kg}$, administered as three intraperitoneal (i.p.) 0.5 $\mathrm{g} / \mathrm{kg}$ injections every 15-20 minutes, with supplements provided as necessary). Following anesthesia induction, the local analgesic Marcaine (bupivacaine, Hospira Healthcare Corporation, Montreal, Quebec, Canada), was administered as $2 \mathrm{mg} / \mathrm{kg}$ subcutaneously (s.c.) under the skull skin along the incision line.

Next, the rat was placed in a stereotaxic apparatus, with the skull surface flat between the bregma and lambda points on the skull. The rat's temperature was monitored using a rectal thermometer and maintained at $36-37^{\circ} \mathrm{C}$ throughout the experiment. Subsequently, an incision 
was made at the midline of the head exposing the skull and small holes were drilled into the skull over the medial geniculate nucleus (MGN; anterior-posterior (AP): -5.5; medial-lateral (ML): +3.8; ventral (V):-5.4 to -6.4) and the ipsilateral A1 (AP: -4.5; ML: +7.0; V: -3.2 to -5.6; all coordinates were based on the rat atlas by Paxinos and Watson, 2007). Two additional holes in the frontal bone were used to secure a ground and reference electrode (jewelry screws).

\subsection{Electrophysiology}

A monopolar recording electrode (125 $\mu \mathrm{m}$ diameter Teflon-insulated stainless steel wire) attached to a microdialysis probe (Mab 2.14.2; $2 \mathrm{~mm}$ active polyether sulfone membrane, 35kDA cut-off; S.P.E. Limited, North York, ON, Canada; electrode tip was about $1 \mathrm{~mm}$ above the probe tip) was lowered into A1. A stimulating electrode (SNE-100 concentric bipolar electrode; Rhodes Medical Instruments, David Kopf, Tujunga, CA) was lowered into the ipsilateral MGN. The final ventral placement for both electrodes was optimized to yield the maximum field postsynaptic potential (fPSPs) amplitude in A1 in response to the single pulse MGN stimulation.

The recording electrode was connected to an amplifier (Model 1800, A-M systems Inc., Microelectrode AC Amplifier) and A-D converter (10 kHz sampling rate; Powerlab 4/s system running Scope Software v4.1.4: AD instruments, Toronto, ON, Canada) to store the signal for subsequent offline analysis. The stimulating electrode was connected to an isolated pulse stimulator (Model 2100, A-M Systems Inc.) delivering constant current stimulation pulses (0.2 ms pulse durations) to the MGN. 


\subsection{Drug application}

The microdialysis probe was connected to a $2.5 \mathrm{~mL}$ Hamilton airtight micro-syringe driven via a micro-dialysis pump (CMA/102, CMA Microdialysis, Norway). The probe was continuously perfused (flow rate of $1.0 \mu 1 / \mathrm{min}$ ) with artificial cerebrospinal fluid (aCSF) composed of: $118.3 \mathrm{mM} \mathrm{NaCl}, 4.4 \mathrm{mM} \mathrm{KCl}, 1.2 \mathrm{mM} \mathrm{MgSO} 4,1.0 \mathrm{mM} \mathrm{NaH} 2 \mathrm{PO} 4,2.5 \mathrm{mM}$, $\mathrm{CaCl} 2,22.1 \mathrm{mM} \mathrm{NaHCO} 3$ and $10.0 \mathrm{mM}$ glucose. Local drug application in A1 was performed by reverse microdialysis, with drugs dissolved in the aCSF and perfused through the probe and the surrounding brain tissue by means of concentration driven diffusion across the dialysis probe membrane. The following drugs were applied to A1 during different experiments: methiothepin maleate $(0.01,0.1$ and $1.0 \mathrm{mM})$; WAY 100635 maleate $(1.0$ and $2.0 \mathrm{mM})$, ketanserin tartrate $(0.1$ and $1.0 \mathrm{mM})$, granisetron hydrochloride $(1.0 \mathrm{mM})$. In control rats, aCSF without any drug was continuously applied to A1 throughout the experiment. All drugs were obtained from Tocris Bioscience, Minneapolis, MN, USA.

\subsection{Data collection}

Following final electrode adjustments, all rats were given at least $10 \mathrm{~min}$ prior to the onset of data collection to allow for the stabilization of electrodes and neural tissue.

Subsequently, an input-output curve was generated for each rat by successive MGN stimulation with increasing intensities $(0.1-1.0 \mathrm{~mA}$ in $0.1 \mathrm{~mA}$ increments). The stimulation intensity that elicited a fPSP amplitude of approximately $50-60 \%$ of the maximum was chosen as the intensity for the subsequent data collection.

Initially, fPSPs were recorded every 30 seconds until a 30 min period of stable (e.g., no systematic increase or decrease in fPSP amplitude) baseline fPSP recordings were collected. 
Next, theta burst stimulation (TBS) was delivered to the MGN in the form of pulse bursts (5 pulses at $100 \mathrm{~Hz} / \mathrm{burst}$ ), with bursts repeated 10 times at a rate of $5 \mathrm{~Hz}$. These trains of 10 bursts were repeated four times every $10 \mathrm{sec}$. Following TBS, fPSPs were recorded (every 30 seconds) for 60 min, after which TBS was applied again. In total, three TBS episodes were delivered for each experiment, each followed by $60 \mathrm{~min}$ of fPSP recordings.

For some groups of rats, fPSP were monitored in the absence of TBS delivery to assess whether drug application alone changed fPSP amplitude over the course of the experiment. For these experiments, baseline fPSPs were recorded in the presence of aCSF for $30 \mathrm{~min}$, followed by drug application (or continuous aCSF) for 3 hours.

\subsection{Histology}

After completion of the electrophysiological procedures, each rat received a supplementary dose of urethane $(1 \mathrm{~mL}$, i.p.) and was subsequently perfused through the heart with $60 \mathrm{~mL}$ of $0.9 \%$ saline, followed by $60 \mathrm{~mL}$ of $10 \%$ phosphate-buffered formalin. The extracted brain was submerged in formalin for about 24 hours prior to sectioning ( $40 \mu \mathrm{m}$ coronal sections) using a cryostat. The tissue was mounted onto dry gelatin-coated microscopic glass slides and an experimenter who was blind to the data of individual experiments verified the accuracy of electrode placements using standard histological techniques and a digital microscope. Data from experiments with electrode placements outside of the target areas were excluded from the subsequent data analyses. 


\subsection{Data Analysis}

The peak amplitude of the two, predominant negative fPSP peaks (Fig. 1) was detected by the software (Scope, v4.1.4) and the voltage difference between the maximum fPSP peak negativity and the baseline voltage sampled prior to the stimulus artifact was computed. The data for each fPSP were averaged over 10 minute intervals (20 fPSPs/epoch) and normalized by dividing each data point by the averaged (pre-TBS) amplitude for that animal. Data from experiments where fPSP amplitude declined to less than $50 \%$ of baseline were excluded from the analysis, due to the non-physiological nature of this decline in synaptic strength.

The data were statistically examined (using SPSS software, v. 23; IBM SPSS Statistics) with a 2factor, mixed model analysis of variance (ANOVA). This analysis had $\alpha=0.05$, independent variable (iv) $1=$ time (averaged 10 min epochs) as the within subjects (repeated) factor; and iv2 $=$ drug condition (drug vs. aCSF) as the between subjects factor. The Greenhouse-Geisser correction was applied in all cases when the assumption of sphericity was violated, as tested by the Mauchly's test of sphericity (using SPSS software). 


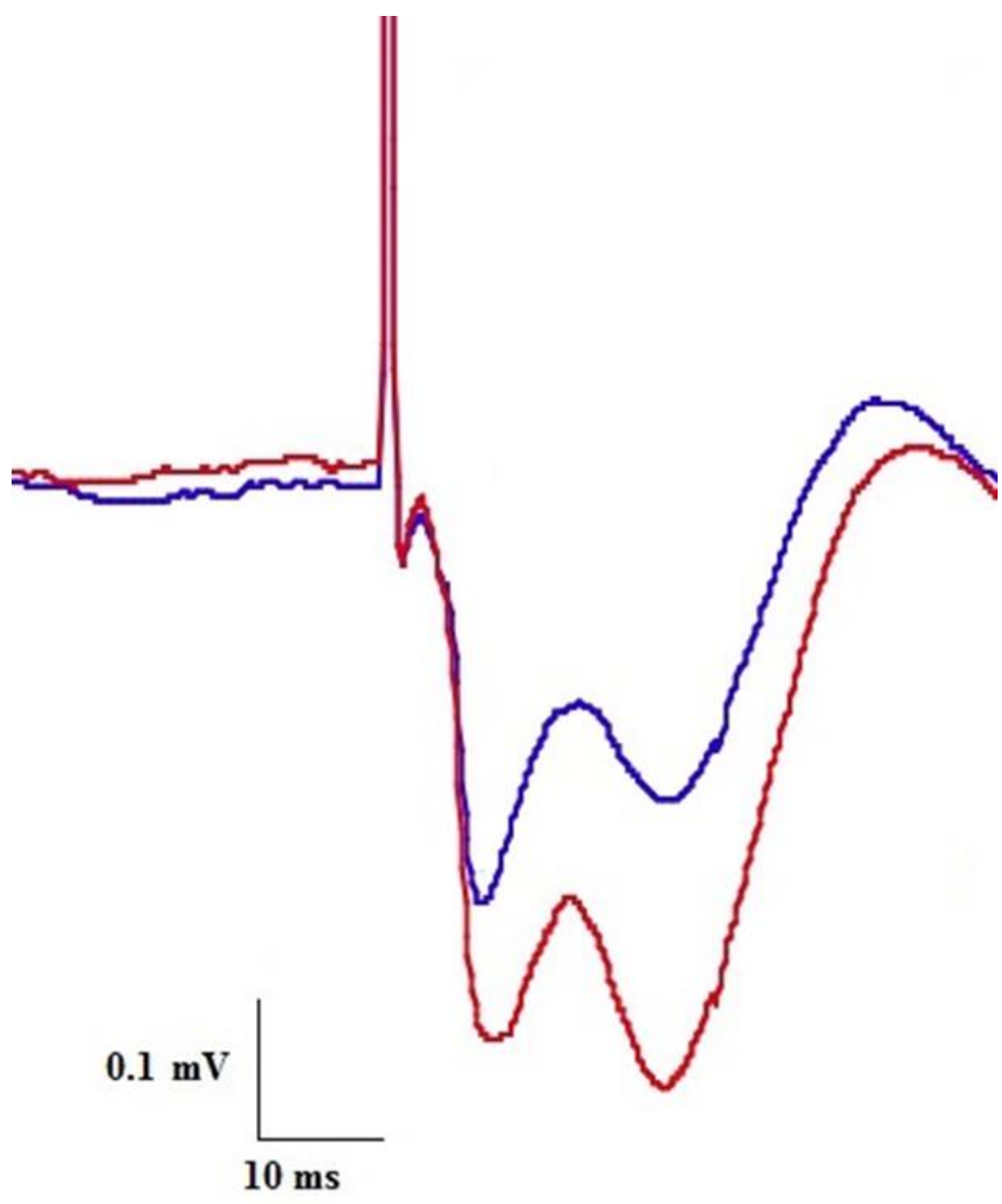

Fig. 1. Typical fPSPs recorded in A1 in response to ipsilateral MGN stimulation in the urethane-anesthetized rat.

Typical fPSPs in A1 consisted of two negative-going peaks with latencies to peak of about 6-9 ms (peak 1) and 15-20 ms (peak 2). The blue trace represents a baseline fPS recording obtained prior to LTP induction; the red trace represents an example of a fPS obtained following LTP induction.

22 


\section{Chapter 3}

\section{Results}

\section{1. fPSP characteristics and LTP during vehicle (aCSF/saline) application}

Single-pulse stimulation of the MGN reliably evoked fPSPs in the ipsilateral A1. These fPSPs consisted of two sequential, negative-going peaks with latencies of about 6-9 and 15-20 ms, respectively (Fig. 1). Prior work using current-source density analyses and pharmacological approaches has suggested that the first and second peak represent the sequential excitation of thalamocortical and intracortical A1 synapses, respectively (Hogsden and Dringenberg, 2009b; Hogsden et al., 2011).

For the pharmacological experiments, two vehicle solutions were used to dissolve various drugs (methiothepin and ketanserin were dissolved in 0.9\% saline; WAY 100635 and granisetron were dissolved in aCSF). An initial analysis of data collected in rats receiving local application of saline $(\mathrm{n}=5)$ or aCSF $(\mathrm{n}=5)$ in A1 by reverse microdialyses did not reveal any statistically significant differences in fPSPs over the course of the experiment between these two vehicle groups (data not shown; main effect of group and group by time interaction all non-significant, $p$ $>0.3$ ). Consequently, rats receiving either saline or aCSF in A1 were combined into a single control/vehicle group $(\mathrm{n}=10)$ for all subsequent comparisons.

For all experiments, TBS to the MGN was delivered after 30 min of stable fPSP recordings were obtained, and TBS was repeated in hourly intervals for a total of 3 stimulation episodes (each followed by 60 min of recordings). During vehicle application $(\mathrm{n}=10$; see above), TBS resulted in an increase in the amplitude of both fPSP peaks (Fig. 1), which reached 127\% (peak 1; Fig. 2A) and 123\% (peak 2; Fig. 2B) of baseline levels during the final 30 min of the experiment (main effect of time for peak 1: $\mathrm{F}(3.56,32.04)=5.1, \mathrm{p}=0.004$; peak 2: 
$\mathrm{F}(2.39,21.48)=3.7, \mathrm{p}=0.035)$. Thus, consistent with previous results, moderate levels of LTP can be induced by thalamic TBS in the A1 of adult rats (Hogsden and Dringenberg, 2009a; Hogsden et al., 2011).

\section{2. $\quad$ Effects of 5-HTR antagonist application in A1 on LTP}

Methiothepin: First, we examined the effect of local application of the broad-acting 5HTR antagonist methiothepin $(0.01 \mathrm{mM}, \mathrm{n}=3 ; 0.1 \mathrm{mM}, \mathrm{n}=3 ; 1.0 \mathrm{mM}, \mathrm{n}=6)$ in LTP induction by TBS of the MGN. In the presence of methiothepin, TBS of the MGN resulted in the suppression of fPSP amplitude, rather than the LTP seen during vehicle application (Fig. 2). For

peak 1, fPSP amplitude was suppressed to $86 \%, 82 \%$, and $76 \%$ of baseline (means for the last 30 min of the experiment; $127 \%$ for vehicle rats, see above) during application of $0.01,0.1$, and 1.0 $\mathrm{mM}$ methiothepin, respectively (Fig. 2A). For peak 2, amplitude decreased to 84\% (0.01 mM), $93 \%(0.1 \mathrm{mM})$, and $89 \%(1.0 \mathrm{mM} ; 123 \%$ for vehicle rats; see above) of baseline for the three drug concentrations (Fig. 2B).

Statistical analyses using ANOVA confirmed that, at $1 \mathrm{mM}$, methiothepin resulted in a significant suppression of amplitude for both fPSP peaks relative to vehicle application (peak 1: main effect of drug, $\mathrm{F}(1,14)=11.82$, $\mathrm{p}<0.01$; drug by time interaction, $\mathrm{F}(2.92,40.92)=6.19$, $\mathrm{p}$ $<0.01$; peak 2: main effect of drug, $\mathrm{F}(1,14)=5.57, \mathrm{p}=0.03$; drug by time interaction, $\mathrm{F}(2.51,35.17)=3.33, \mathrm{p}=0.038)$. At $0.1 \mathrm{mM}$, methiothepin still resulted in a significant suppression of peak 1 (main effect of drug and drug by time interaction both $\mathrm{p}<0.025$ ), but not of peak 2. At $0.01 \mathrm{mM}$, methiothepin, no longer produced statistically significant changes of either fPSP peak compared to the vehicle condition (all p's $>0.05$ ). 
An additional ANOVA was computed to assess whether there were significant changes in fPSP amplitude over time during application the high concentration of methiothepin $(1 \mathrm{mM})$. This analysis did not reveal significant main effects of time for either peak of the fPSP; peak 1: $\mathrm{F}(1.37,6.82)=2.75, \mathrm{p}=0.14$; peak 2: $\mathrm{F}(1.86,9.30)=1.43, \mathrm{p}=0.29$

WAY 100635: Next, we examined the effect of selective blockade of 5-HT1A receptors by application of WAY 100635 in A1 $(1 \mathrm{mM}, \mathrm{n}=12)$. In contrast to methiothepin, WAY 100635 did not exerted significant effects on LTP induction by TBS of the MGN, with peak 1 (Fig. 3A) and peak 2 (Fig. 3B) reaching $113 \%$ and $118 \%$, respectively, of baseline during the final 30 min of the experiment.

An ANOVA confirmed the lack of significant effects of 1 mM WAY 100635 on LTP (peak 1: main effect of drug, $\mathrm{F}(1,20)=2.71, \mathrm{p}=0.12$; drug by time interaction, $\mathrm{F}(4.46,89.27)=$ $1.33, \mathrm{p}=0.26$; note the main effect of time was significant, indicative of successful LTP induction across both conditions, $\mathrm{F}(4.46,89.27)=9.16, \mathrm{p}<0.01$; peak 2: main effect of drug, $\mathrm{F}(1,20)=0.28, \mathrm{p}=0.60 ;$ drug by time interaction, $\mathrm{F}(3.33,66.63)=0.42, \mathrm{p}=0.76$; main effect of time, $\mathrm{F}(3.33,66.63)=8.41, \mathrm{p}<0.01)$. In a small group of rats $(\mathrm{n}=3)$, the effects of $2 \mathrm{mM}$ WAY 100635 were tested, but even this high concentration did not yield clear changes in amplitude of either fPSP peak (Fig. 3 p's $>0.2$ for drug effect and drug by time interaction).

Ketanserin: Application of the 5- $\mathrm{HT}_{2} \mathrm{R}$ antagonist ketanserin $(0.1 \mathrm{mM}, \mathrm{n}=4 ; 1 \mathrm{mM}, \mathrm{n}=$ 3) produced effects very similar to those seen in with methiothepin application. That is, LTP induction was suppressed for both peaks of the fPSPs (Fig. 4). For the lower concentration (0.1 $\mathrm{mM}$ ), the amplitude of peak 1 and peak 2 decreased to $70 \%$ and $92 \%$ of baseline, respectively; at $1.0 \mathrm{mM}$, the two peaks showed a further suppress to $63 \%$ and $69 \%$ (Fig. 4; means for the final 30 min of the experiment). 
ANOVA confirmed that fPSP amplitude during application of either 0.1 or $1.0 \mathrm{mM}$ ketanserin was significant lower compared to vehicle application $(\mathbf{0 . 1} \mathbf{~ m M}$, peak 1: main effect of drug, $\mathrm{F}(1,12)=21.93, \mathrm{p}<0.01$; drug by time interaction, $\mathrm{F}(3.83,45.93)=6.68, \mathrm{p}<0.01 ; \mathbf{0 . 1}$ mM, peak 2: main effect of drug, $F(1,12)=3.29, \mathrm{p}=0.10$; drug by time interaction, $\mathrm{F}(2.67,31.98)=3.20, \mathrm{p}=0.04 ; \mathbf{1 . 0} \mathbf{~ m M}$, peak 1: main effect of drug, $\mathrm{F}(1,12)=39.08, \mathrm{p}<0.01$; drug by time interaction, $F(3.50,41.94)=7.60, p<0.01 ; 1.0 ~ m M$, peak 2: main effect of drug, $\mathrm{F}(1,11)=11.45, \mathrm{p}<0.01$; drug by time interaction, $\mathrm{F}(2.71,29.76)=3.67, \mathrm{p}=0.03)$.

An additional ANOVA was computed to assess whether there were significant changes in fPSP amplitude over time during application the high concentration of ketanserin $(1 \mathrm{mM})$. This analysis did not reveal significant main effects of time for either peak of the fPSP; peak 1: $\mathrm{F}(1.68,5.04)=4.80, \mathrm{p}=0.07$; peak 2: $\mathrm{F}(1.80,3.59)=1.54, \mathrm{p}=0.32$

Granisetron: The last set of LTP experiments evaluated the role of $5-\mathrm{HT}_{3} \mathrm{R}$ by cortical application of granistron $(1 \mathrm{mM}, \mathrm{n}=12)$. Interestingly, granistron resulted in a blockade of LTP induction at thalamocortical synapses (Fig. 5A; fPSP amplitude at 103\% of baseline during final 30 min of experiment; $127 \%$ for vehicle, see above), while LTP at intracortical synapses remained completely intact (Fig. 5C; amplitude at 126\% of baseline; 123\% for vehicle, see above).

ANOVA confirmed that granisetron exerted a significant effect on the first peak of the fPSP, while peak 2 was not different between rats receiving application granisetron and vehicle (peak 1: main effect of drug, $\mathrm{F}(1,20)=6.51, \mathrm{p}=0.02$; drug by time interaction, $\mathrm{F}(4.56,91.17)=$ 3.07, $\mathrm{p}=0.02$; main effect of time, $\mathrm{F}(4.56,91.17)=7.08, \mathrm{p}<0.01$; peak 2: main effect of drug, $\mathrm{F}(1,20)=3.42, \mathrm{p}=0.08$; drug by time interaction, $\mathrm{F}(3.32,66.27)=2.42, \mathrm{p}=0.07$; main effect of time, $\mathrm{F}(3.32,66.27)=12.69, \mathrm{p}<0.01)$. 


\subsection{Effects of 5-HTR antagonist on baseline (pre-TBS) fPSP amplitude}

It is possible that 5-HTRs in A1 also participate in the regulation of baseline (nonpotentiated/depressed) synaptic transmission. Thus, we also measure and compared the fPSP amplitude recorded during the 30 min baseline period of the experiment (i.e., during drug application, but prior to TBS delivery) in all experimental groups.

During vehicle application and prior to LTP induction, the mean amplitude of the first and second fPSP peak was $0.41 \mathrm{mV}$ and $0.39 \mathrm{mV}$, respectively (Fig. 6). Application of methiothepin, ketanserin, or WAY 100635 did not result in significant changes in the amplitude of either fPSP peak (Fig. 6). However, during granisetron application, the amplitude of both fPSP peaks was much higher compared to the vehicle condition (Fig 6; $0.74 \mathrm{mV}$ and $0.78 \mathrm{mV}$ for peak 1 and peak 2 , respectively).

To further investigate this effect, two additional groups of rats were tested that did not receive TBS. In one group $(\mathrm{n}=3)$, fPSPs were monitored during continuous application of aCSF for 3.5 hours, while a second group $(n=5)$ received aCSF for the first 30 min, followed by 3 hours of granisetron application $(1 \mathrm{mM})$. During continuous aCSF application, fPSPs stayed relatively stable over the course of the experiment, with amplitude at $100.3 \%$ and $112 \%$ of baseline for the first and second peak, respectively, during the last 30 min of the experiment (Fig. 7). In contrast, granisetron application resulted in a clear increase in the amplitude of both peaks during the 3 hour application period, which reached $126 \%$ and $187 \%$ of baseline for peak 1 and peak 2, respectively (Fig. 7; peak 1 is based on an $\mathrm{n}=4$, since this peak could not be resolved in one animal). 
The ANOVA confirmed that fPSP amplitude was significantly higher during granisetron application relative to the vehicle condition, as indicated by the significant drug by time interaction for both fPSP peaks (peak 1: $\mathrm{F}(2.36,11.79)=4.98, \mathrm{p}=0.023$; peak 2: $\mathrm{F}(1.69,10.16)$ $=5.06, \mathrm{p}=0.034)$. 


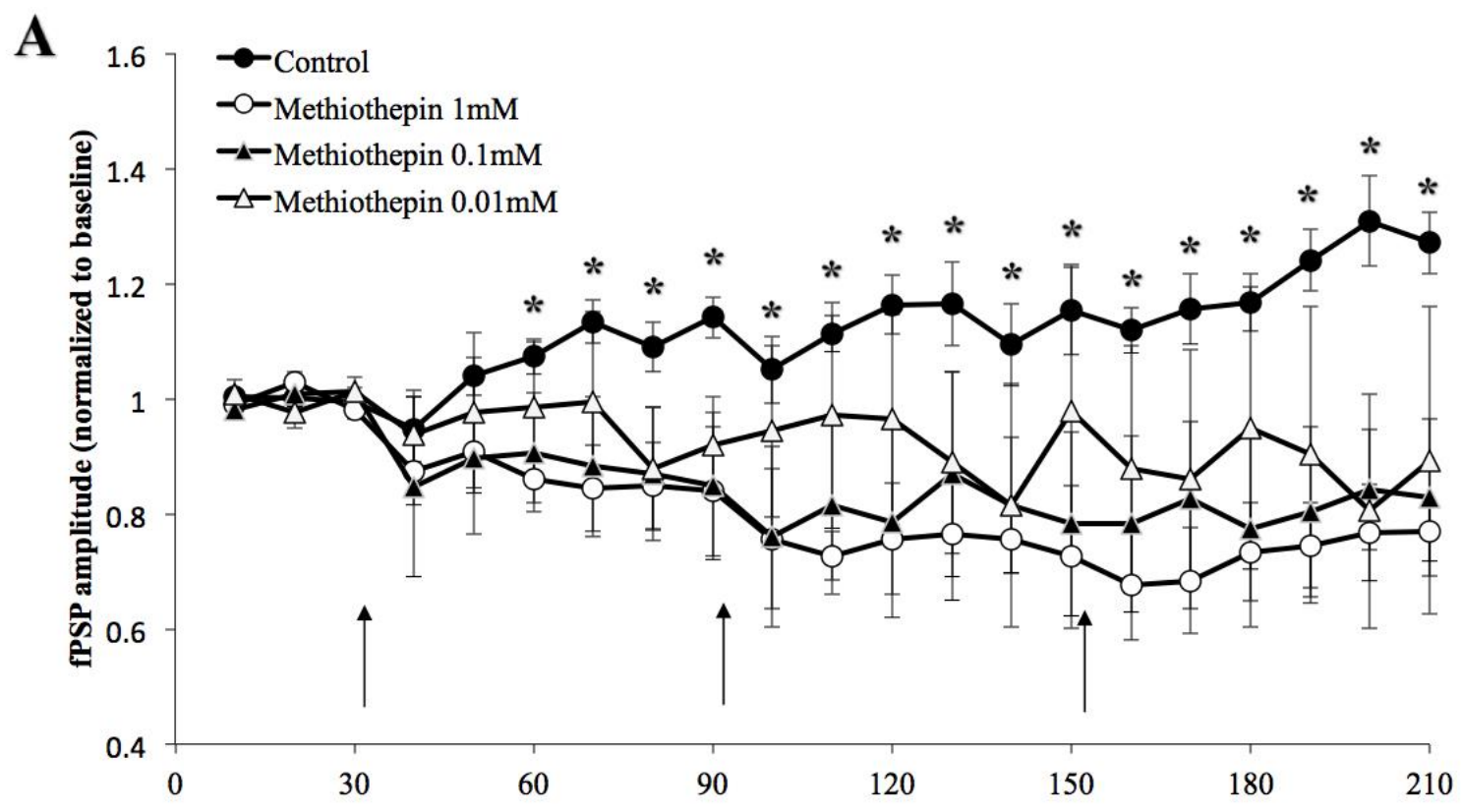

B

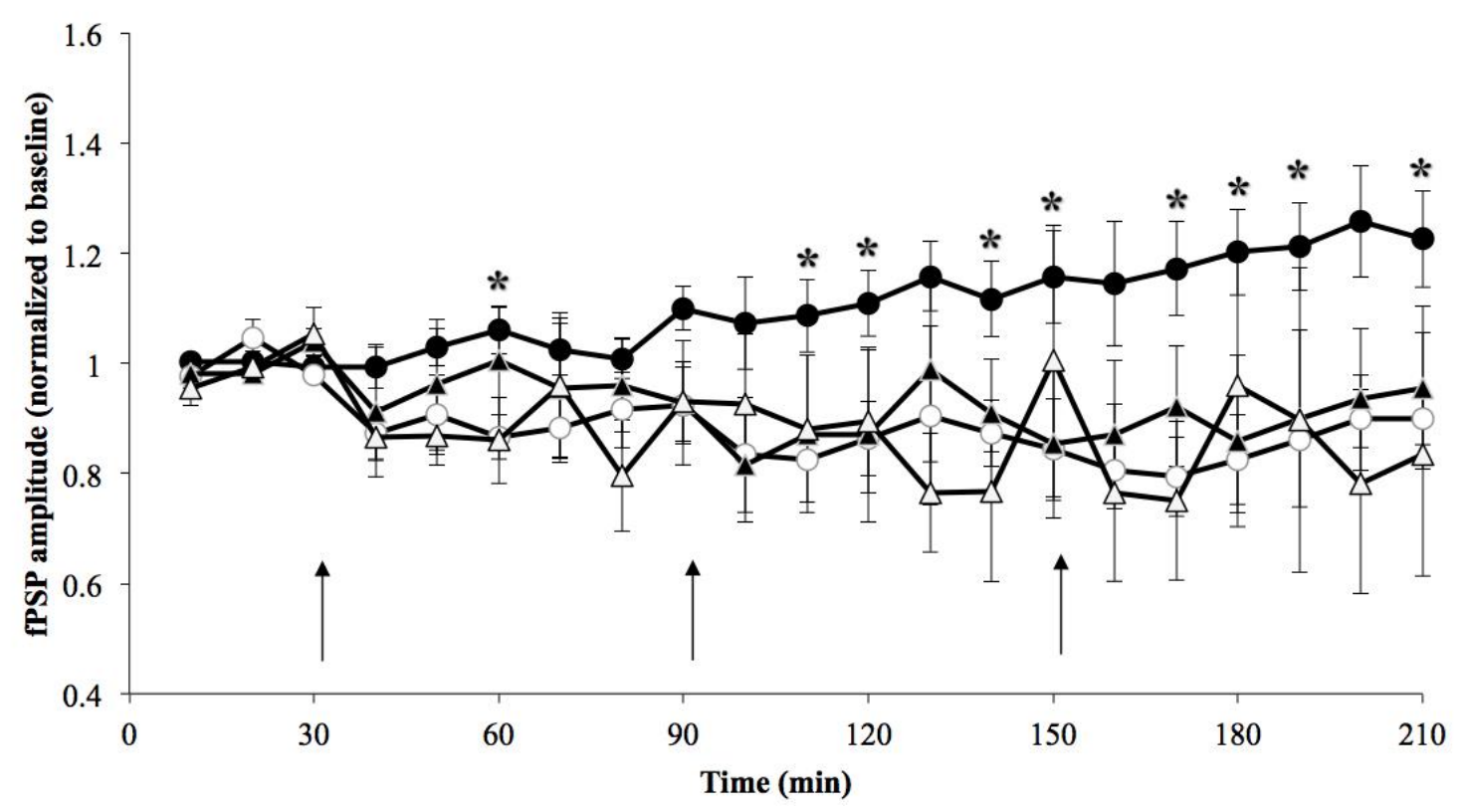

Fig. 2. Effects of cortical application of methiothepin on LTP induction in A1.

In the presence of vehicle application (Control: $\mathrm{n}=10$; all drugs applied by reverse microdialysis in A1), theta-burst stimulation (at arrows) delivered to the MGN resulted in moderate potentiation/LTP of the first peak (panel A) and second peak (panel B) of fPSPs recorded in A1. Application of methiothepin $(0.01 \mathrm{mM}, \mathrm{n}=3 ; 0.1 \mathrm{mM}, \mathrm{n}=3 ; 1.0 \mathrm{mM}, \mathrm{n}=6)$ suppressed LTP. $*$ indicates significant $(\mathrm{p}<0.05$; simple effects test) difference between control and $1.0 \mathrm{mM}$ methiothepin. 
A

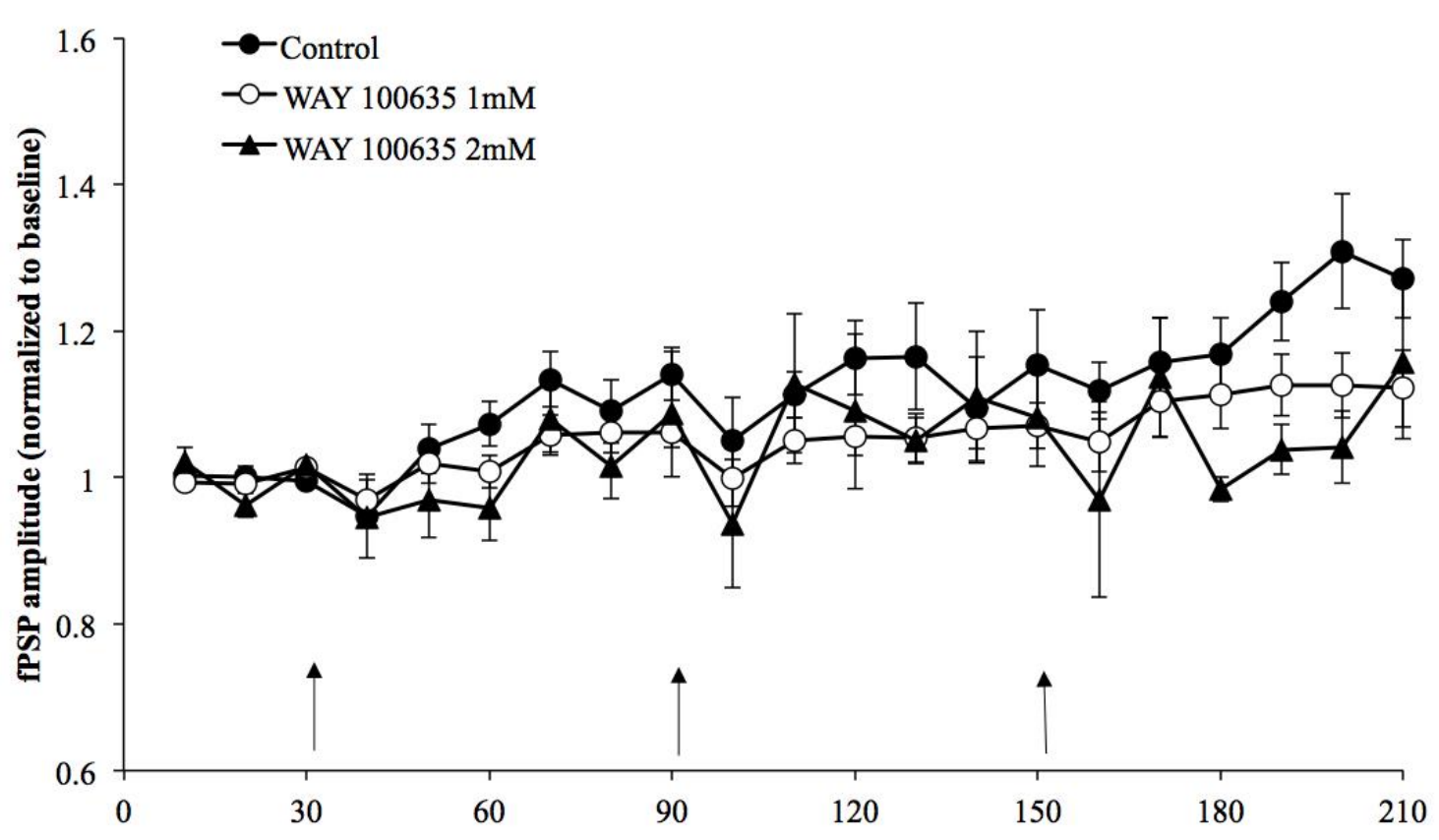

B

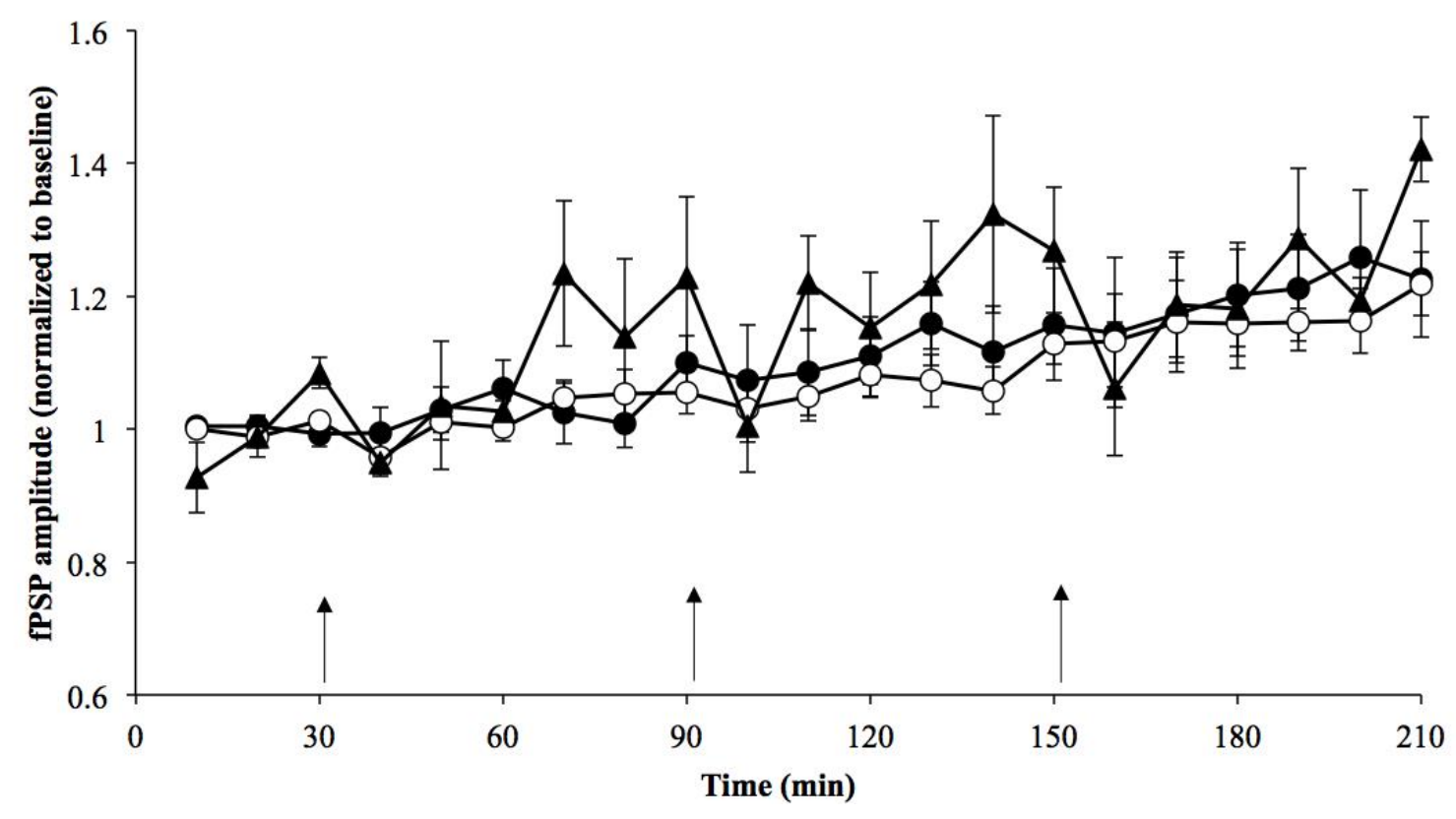

Fig. 3. Effects of cortical application of WAY 100635 on LTP induction in A1.

Application of WAY $100635(1 \mathrm{mM}, \mathrm{n}=12 ; 2 \mathrm{mM}, \mathrm{n}=3)$ in A1 did not result in any significant changes in LTP induction of either the first (A) or second (B) fPSP peak compared to control animals ( $\mathrm{n}=10$; same group as shown in Fig. 2). 

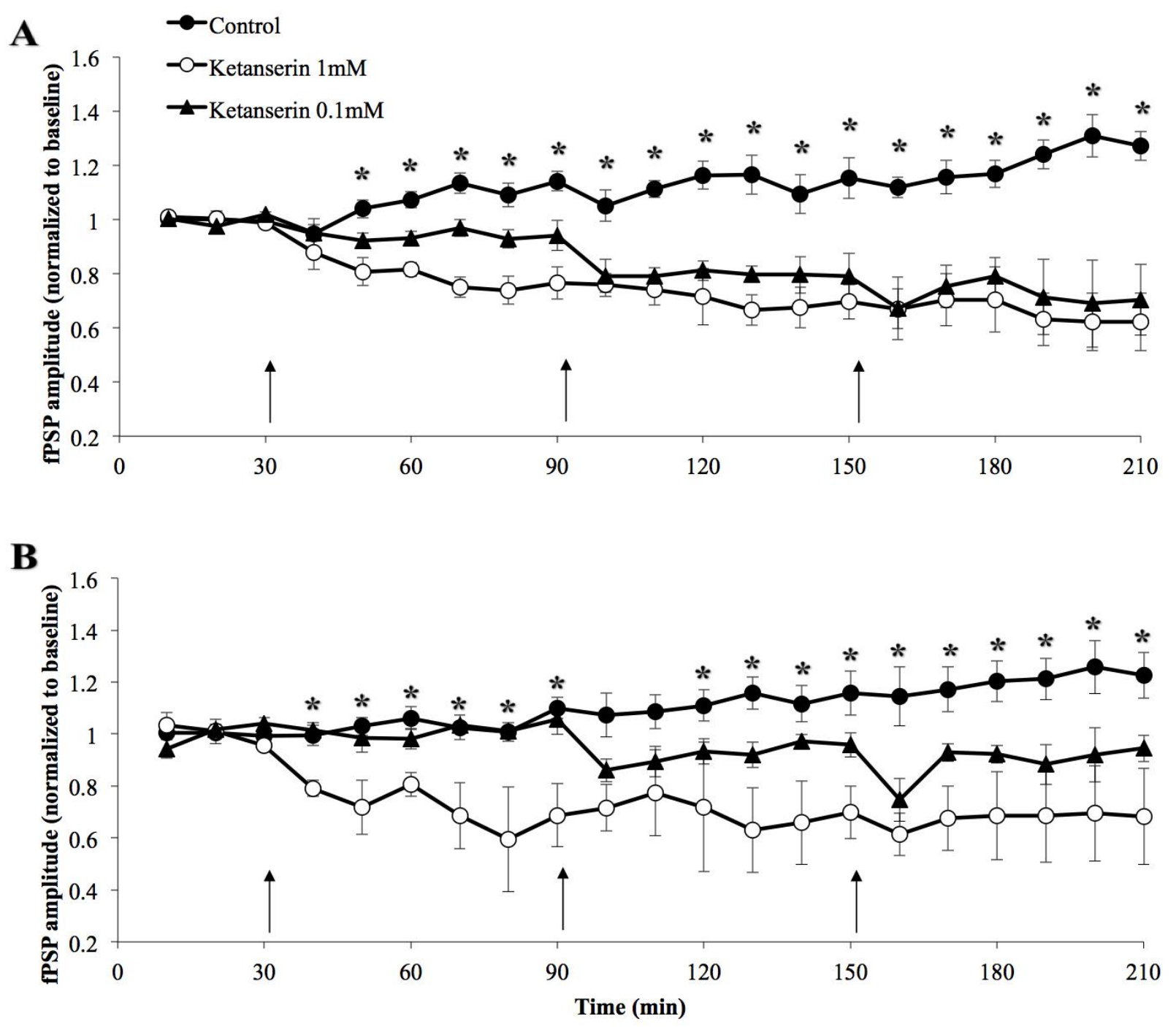

Fig. 4. Effects of cortical application of ketanserin on LTP induction in A1.

Compared to control animals (same group as in Fig. 2), application of ketanserin $(0.1 \mathrm{mM}, \mathrm{n}=4$; $1.0 \mathrm{mM}, \mathrm{n}=3$ ) resulted in LTP suppression for both the first (A) and second (B) fPSP peak, similar to the effect observed with methiothepin application. ${ }^{*}$ indicates significant $(\mathrm{p}<0.05$; simple effects test) difference between control and $1.0 \mathrm{mM}$ ketanserin. 

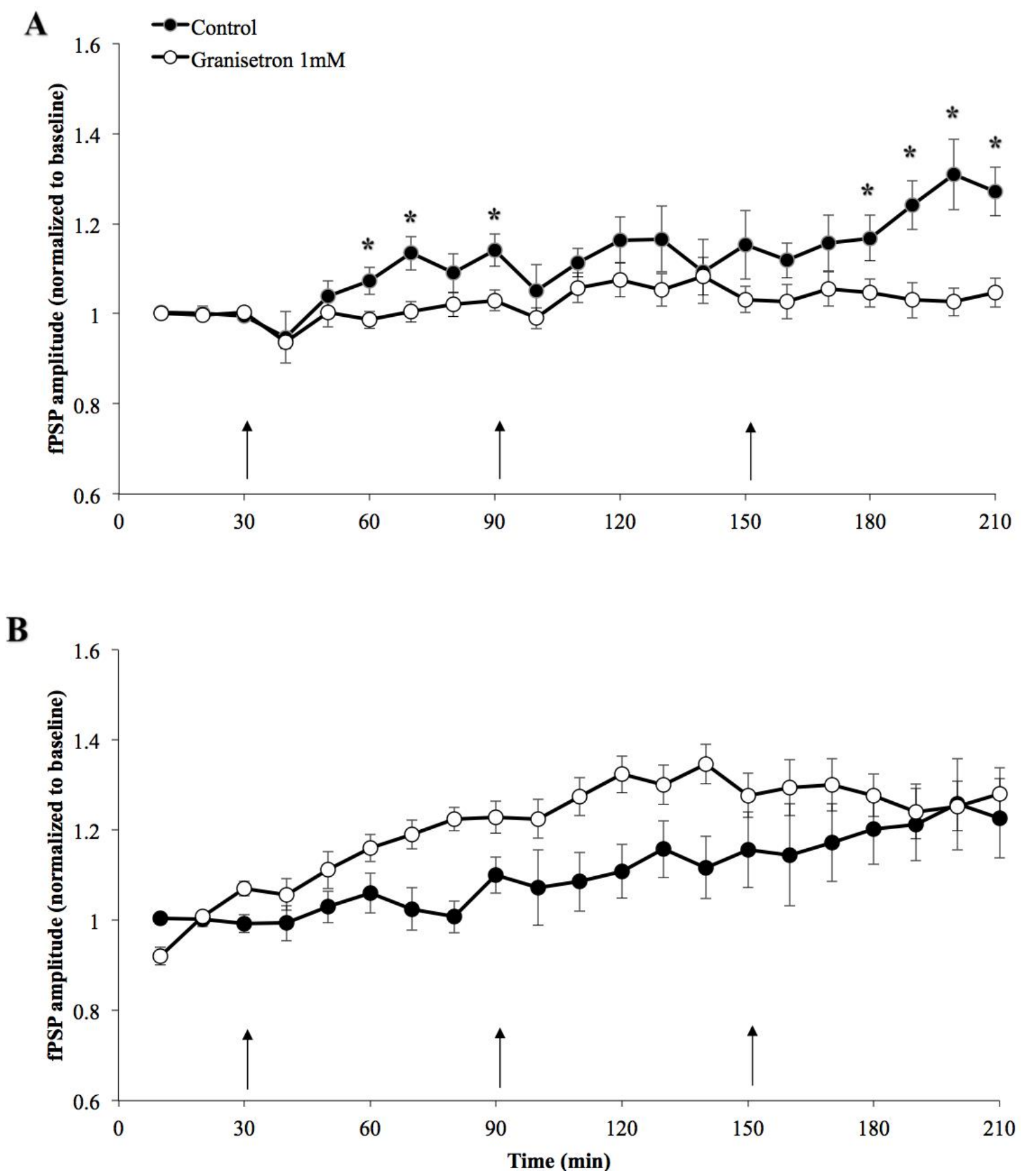

Fig. 5. Effects of cortical application of granisetron on LTP induction in A1.

Compared to control animals (same group as in Fig. 2), application of granisetron (1.0 mM, n = 12) completely abolished LTP of the first fPSP peak (A), while LTP of the second peak (B) was intact. * indicates significant ( $\mathrm{p}<0.05$; simple effects test) difference between control and 1.0 $\mathrm{mM}$ granisetron. 

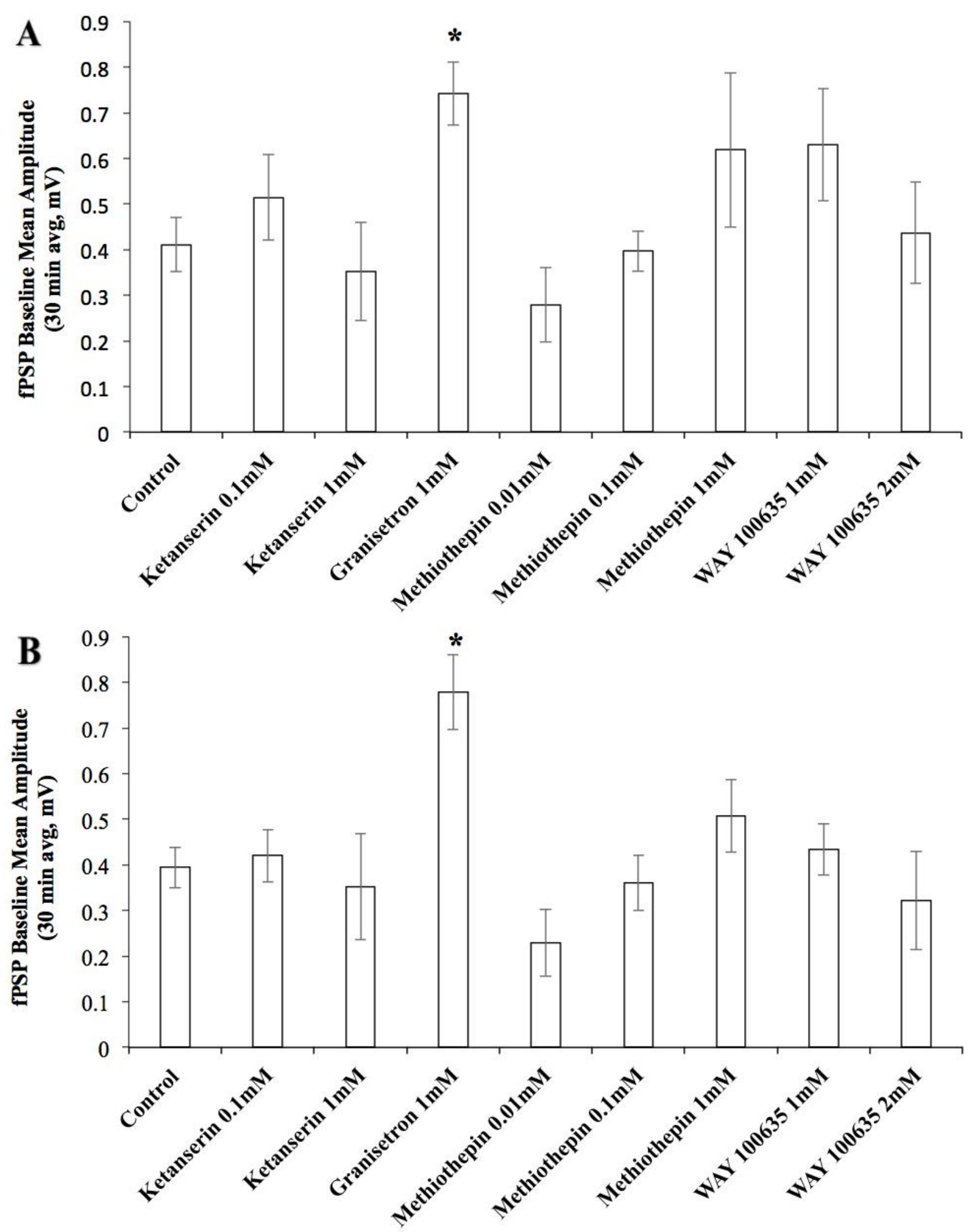
Fig. 6. Amplitude of fPSPs in all drug conditions prior to LTP induction.

During vehicle (Control) Mean fPSP amplitude during the 30 min baseline (pre-TBS delivery) recording period was $0.41 \mathrm{mV}$ and $0.39 \mathrm{mV}$ for the first $(\mathbf{A})$ and second PPSP peak (B), respectively. Methiothepin, ketanserin, or WAY 100635 did not significantly alter baseline fPSP amplitudes, but granisetron application resulted in a pronounced increase in the amplitude of both fPSP peaks ( $0.74 \mathrm{mV}$ and $0.78 \mathrm{mV}$ for peak 1 and peak 2 , respectively). * indicates significant ( $\mathrm{p}<0.05$; simple effects test) difference between control and $1.0 \mathrm{mM}$ granisetron. 
A
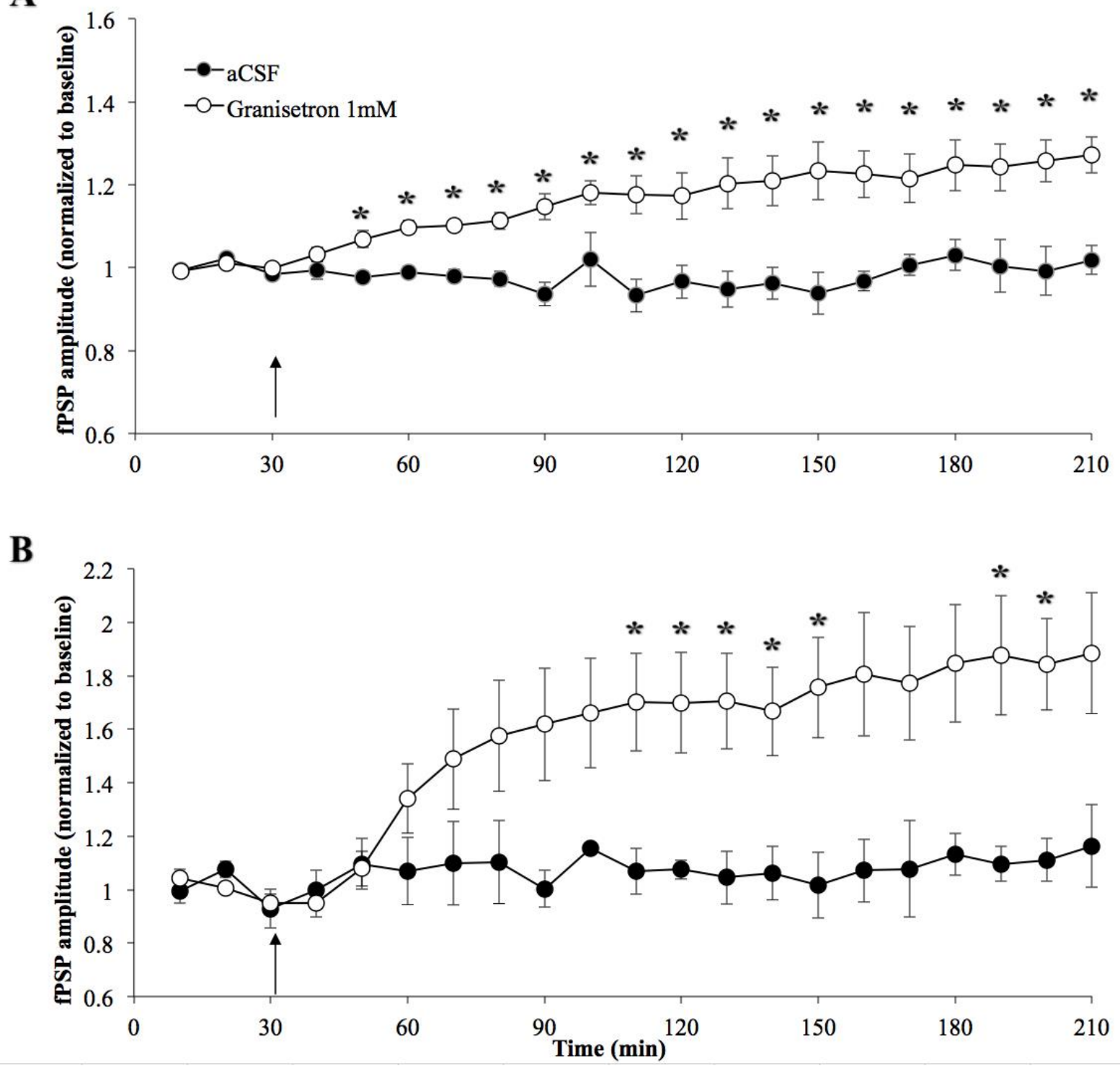

Fig. 7. Effects of cortical application of granisetron on fPSP amplitude in A1.

Amplitude of the first (A) and second fPSP peak (B) remained relatively stable during continuous application of aCSF for 3.5 hours $(n=3)$. In contrast, granisetron application $(n=5$; $1 \mathrm{mM}$; application start at arrow) resulted in a significant increase in the amplitude of both fPSP peaks (note that these rats did not receive TBS to induce LTD). * indicates significant ( $p<0.05$; simple effects test) difference between aCSF and granisetron. 


\section{Chapter 4}

\section{Discussion}

The present experiments examined the role of several classes of 5-HTRs on plasticity induction in the thalamocortical auditory system of adult, urethane-anesthetized rats. Delivery of TBS to the MGN reliably induced moderate levels of synaptic potentiation of fPSPs recorded in A1. Local, cortical application (by reverse microdialysis) of the broad-acting 5-HTR antagonist methiothepin suppressed LTP at both thalamocortical and intracortical synapses, an effect that was mimicked by the selective $5-\mathrm{HT}_{2} \mathrm{R}$ antagonist ketanserin, but not the $5-\mathrm{HT}_{1 \mathrm{~A}} \mathrm{R}$ blocker WAY 100635. Interestingly, blockade of 5-HT3Rs by granisetron blocked LTP at thalamocortical, but not intracortical A1 synapses. Further, in the absence of TBS, granisetron application resulted in a pronounced increase of the amplitude of both fPSP peaks, suggestive of an inhibitory role of 5$\mathrm{HT}_{3} \mathrm{R}$ in controlling baseline synaptic transmission at thalamocortical and intracortical A1 synapses. Together, these results indicate that 5-HTRs exert important gating functions by influencing the induction and direction of long-term plasticity at synapses of the fully matured A1 of mammalian species.

The recordings obtained in A1 following single-pulse stimulation of the MGN consisted of fPSPs that exhibited two, distinct peaks, with latencies to peak of about 6-9 and 15-20 ms, respectively (Fig. 1). Both fPSP peaks evoked in A1 by ipsilateral MGN stimulation are negative components with an amplitude of about $0.4 \mathrm{mV}$. Previous studies employing current source density analysis and pharmacological manipulations have been conducted in order to identify the synaptic mechanisms and origin of these two peaks presented in fPSPs recorded in the A1 of anesthetized rats. 
In one investigation (Hogsden \& Dringenberg, 2009b), fPSPs were recorded throughout the entire dorsal-ventral extent of A1 (in 100-micron steps) and current source density analysis was used to identify the current sinks (i.e., positive current entering cells, creating negative extracellular potentials; see Vanderwolf, 1990) present at different cortical depth and layers. The results of this study indicate that the first fPSP peak corresponds to a current sink in deeper cortical layers (around layer IV) that receive direct inputs from thalamic terminals, while the second fPSP peak is driven by currents sinks in layers II/III of A1, which receive inputs from deeper cortical layers (Hogsden \& Dringenberg, 2009b). Subsequent pharmacological experiments have confirmed and extended these observations; local application of pharmacological agents that inhibit intracortical transmission while preserving activity of thalamocortical terminals (a combination of the GABA receptor agonist muscimol to inhibit cortical activity; and the GABA-B receptor antagonist SCH 50911 to protect thalamocortical terminals from the effects of muscimol) results in a preferential suppression of the second fPSP peak, consistent with the involvement of intracortical mechanisms in its generation (Hogsden et al., 2011). It is also noteworthy that both fPSP peaks are largely abolished by local application of CNQX (Hogsden \& Dringenberg, 2009), suggesting that these fPSPs are mediated by excitatory, AMPA-receptor mediated currents in A1.

We were surprised that application of WAY 100635, a highly selective antagonist at 5$\mathrm{HT}_{1 \mathrm{~A}} \mathrm{Rs}$ (Forster et al., 1995), did not affect LTP induction in A1. 5- $\mathrm{HT}_{1 \mathrm{~A}} \mathrm{Rs}$ act as somatodendritic autoreceptors that suppress 5-HT release, but are also present at postsynaptic locations in the forebrain (Barnes and Sharp, 1999; Nichols and Nichols, 2008). Activation of 5$\mathrm{HT}_{1 \mathrm{~A}} \mathrm{Rs}$ has been implicated in plasticity/LTP modulation in several forebrain areas, including the hippocampus, visual cortex, and prefrontal cortex. For example, in V1, 5- $\mathrm{HT}_{1 \mathrm{~A}} \mathrm{Rs}$ have been 
shown to inhibit LTP induction in vitro and in vivo (Dringenberg and Gagolewicz, 2016; Edagawa et al., 1998; Kim et al., 2006), suggesting that 5-HT may participate in the stabilization of synaptic connectivity in the mature cortex. Similarly, in the prefrontal cortex, $5-\mathrm{HT}_{1 \mathrm{~A}} \mathrm{Rs}$ activation can inhibit calcium influence though NMDA channels, thereby reducing the probability of LTP induction (and favouring LTD; Meunier et al., 2017). Based on the present results, 5- $\mathrm{HT}_{1 \mathrm{~A}} \mathrm{Rs}$ do not perform similar functions at either thalamocortical or intracortical synapses in the mature A1, at least under the present, experimental conditions.

Application of the broad-acting 5-HTR antagonist methiothepin (Bard et al., 1996; Hoyer et al., 1994; Peroutka, 1990) suppressed the TBS-induced response of both thalamocortical and intracortical A1 synapses, an effect that was mimicked by the selective $5-\mathrm{HT}_{2} \mathrm{R}$ antagonist ketanserin (Leysen et al., 1982; Peroutka, 1990). Thus, 5-HT2 Rs appear to play a critical role in LTP induction at neocortical synapses. Prior work is consistent with this interpretation, in that 5$\mathrm{HT}_{2} \mathrm{R}$ stimulation has been shown to enhance LTP induction at synapses in the basolateral amygdala and hippocampal CA1 field in vitro (Chen et al. 2003; Rozas et al. 2012).

5-HT ${ }_{2} \mathrm{Rs}$ are widely distributed throughout the neocortex and most cortical layers (layers II to VI; Hamada et al., 1998; Jakab et al., 2000). Interestingly, some types of 5-HT 2 Rs (e.g., 5$\mathrm{HT}_{2 \mathrm{~A}} \mathrm{Rs}$ ) are located on both cortical pyramidal cells and GABAergic interneurons (Jakab et al., 2000), as well as presynaptically on terminals of thalamocortical axons (Barre et al., 2016). Thus, there are a number of complementary mechanism by which these receptors can modulate cellular excitability and plasticity induction in cortical networks. Activation of $5-\mathrm{HT}_{2} \mathrm{Rs}$ in neocortical pyramidal cells often (but not always) elicits excitatory effects, including increases in spontaneous excitatory postsynaptic currents, cellular depolarization, and inhibition of the afterhyperpolarization current that follows neuronal discharge (Aghajanian and Marek, 1997; 
Araneda and Andrade, 1991; Celada et al., 2013; Davies et al., 1987; Newberry et al., 1999). Blockade of $5-\mathrm{HT}_{2} \mathrm{Rs}$ by ketanserin can result in a facilitation of inhibitory responses to 5-HT application (Lakoski and Aghajanian, 1985). Recent work has shown that activation of presynaptic 5-HT $\mathrm{H}_{2 \mathrm{~A}} \mathrm{Rs}$ on thalamocortical fibers (terminating in the prefrontal cortex) acts to facilitate NMDA-mediated transmission (Barre et al., 2016). The precise mechanisms mediating the LTP suppression seen during methiothepin or ketanserin application remain to be elucidated; however, the observation that LTP at thalamocortical A1 synapses involves a presynaptic component (as measured by changes in paired-pulse ratios; Soutar et al., 2016) is consistent with a potential, presynaptic (at least in part) locus of this effect.

Application of granisetron, a potent antagonist of 5-HT ${ }_{3} \mathrm{Rs}$ (Plosker and Goa, 1991; Sanger and Nelson, 1989) exerted a surprising, selective effect on plasticity induction by blocking LTP of the first, but not the second peak of cortical fPSPs. Thus, it appears that 5$\mathrm{HT}_{3} \mathrm{Rs}$ play an important role in the gating of plasticity at thalamocortical, but not intracortical synapses in $\mathrm{A} 1.5-\mathrm{HT}_{3} \mathrm{Rs}$ are ligand-gated ion channels mediating rapid neuronal depolarization (Barnes and Sharp, 1999; Celada et al., 2013) and are expressed widely throughout the forebrain, including the neocortex (Barnes and Sharp, 1999; Kilpatrick et al., 1987; Morales et al., 1998). Since many $5-\mathrm{HT}_{3} \mathrm{Rs}$ are located on GABAergic interneurons in the hippocampus and neocortex (Jakab et al., 2000; Morales et al., 1996), they are able to profoundly shift the excitatoryinhibitory balance of cortical circuits. At present, it is not known if the impairment of LTP induction by granisetron involves changes in inhibitory tone on A1. It would appear that a blockade of 5-HT 3 Rs on GABAergic cells should result in cortical disinhibition and enhanced plasticity induction, rather than the LTP impairment observed in our experiments. Future experiments measuring both excitatory and inhibitory currents and LTP in principal cells and 
different classes of interneurons are required to more fully elucidate the mechanisms involved in LTP gating by $5-\mathrm{HT}_{3} \mathrm{Rs}$ in the rodent A1.

We also noted that the application of granisetron resulted in a clear enhancement of baseline (i.e., non-potentiated) fPSP amplitude, which reached $126 \%$ and $187 \%$ of baseline levels for the first and second fPSP peak, respectively (it is noteworthy that these levels of facilitation are greater than those seen during the induction of LTP in A1). Prior work has demonstrated the involvement of $5-\mathrm{HT}_{1 \mathrm{~A}} \mathrm{Rs}$ and $5-\mathrm{HT}_{2 \mathrm{~A}} \mathrm{Rs}$ in modulating inhibitory transmission in layers II/III of A1 (Garcia-Oscos et al., 2015). The present data extend these findings by showing that $5-\mathrm{HT}_{3} \mathrm{Rs}$ also exert a powerful role in controlling A1 synaptic activity by inhibiting thalamocortical and intracortical A1 synapses, an effect that was relieved during granisetron application. It is possible that this inhibitory role of $5-\mathrm{HT}_{3} \mathrm{Rs}$ is directly related to the presence of these receptors on GABA-containing interneurons in A1, as discussed previously.

In summary, the role of 5-HT and different types of 5-HTRs in gating plasticity induction in neocortical circuits remains unclear, with variable and seemingly contradictory effects reported for LTP induction in cortical sensory fields (e.g., V1, enhanced LTP: Inaba et al., 2009; Kojic et al., 1997, 2000; Park et al., 2012; impaired LTP: Edagawa et al., 1998, 2000; Gagolewicz and Dringenberg, 2016; Kim et al., 2006). The use of different species, ages of experimental subjects, induction protocols, and electrophysiological recordings obtained in different cortical layers likely all contribute to the heterogeneous results obtained in previous studies.

The results of the present set of experiments reveal a consistent picture in that the blockade of two main classes of 5-HTRs (5-HT2 Rs and 5-HT 3 Rs) impairs LTP. Thus, it appears that the tonic activation of these receptors exerts a permissive and/or facilitating influence over 
LTP induction in the A1 of adult rodents. Pharmacological treatments targeting serotonergic transmission (e.g., selective serotonin reuptake inhibitors) have shown promise in enhancing synaptic plasticity in the mature nervous system, with potential therapeutic effects, such as the restoration of visual functions in animal models of amblyopia (Ruiz-Perera et al., 2015; Vetencourt et al., 2008). Given that LTP in A1 is most pronounced in juvenile animals and declines into adulthood (Hogsden and Dringenberg, 2009a), some of the effects described here may be relevant to pharmacological strategies for restoring heightened (perhaps juvenile-like) levels of synaptic plasticity in the fully mature nervous system of adult mammals (e.g., Bavelier et al., 2010).

The experiments summarized in this thesis add to the growing body of literature demonstrating that the auditory system of adult animals retains a significant potential for the induction of synaptic plasticity (Tzounopoulos et al., 2012). For, example, LTP and LTD have been observed in the fully matured auditory cortex of rodents, where they likely play a role in learning related plasticity, such as experience-induced changes in the tonotopic organization of A1 (Tzounopoulos et al., 2012). The experimental results reported here show that 5-HTRs can act on plasticity induction in A1. As such, this work may have important implications for attempts to enhance plasticity in the mature brain, e.g., by restoring heightened, juvenile-like levels of LTP in the mature A1.

Synaptic plasticity is now known as an essential contributor to the success of cochlear implants to restore auditory perceptual functions in patients suffering from hearing loss (Fallon et al., 2002). However, the success cochlear implants is variable, given that implants provide patients only with an abnormal, impoverished acoustic input (Fallon et al., 2002). Also, the effectiveness of cochlear implants often decreases with age, an effect that likely relates to the 
loss of plasticity in the central auditory pathway, which cannot adapt to the acoustic signals provided by the implant. If implanted under 12 months of age, the communication skills of congenitally deaf children will improve and begin to match those of children without hearing impairments (Fallon et al., 2002). In contrast, patients receiving cochlear implants as young adults often continue to show perceptual deficits, including poor speech perception and abnormal pitch perception (Fallon et al., 2002).

Work in rats has shown that, even though the mature A1 does exhibit LTP, there is a clear, age-related decline in LTP over postnatal life (Hogsden et al., 2009). Based on the assumption that a loss of central auditory plasticity reduces the effectiveness of cochlear implants, it is tempting to speculate that an enhancement of plasticity could improve the clinical outcomes for patients receiving implants, particularly if this happens in adulthood or later life. The present set of experiments has shown that 5-HT2Rs and 5-HT3Rs activation exerts a clear effect on LTP induction at A1 synapses. Thus, it is possible that 5-HT2R and 5-HT3R agonists can be used to enhance the LTP levels in the A1 of the adult or aged brain. Ultimately, identifying novel (pharmacological and/or others) strategies to enhance synaptic plasticity in the mature auditory cortex may help adults/older adults to better adapt to cochlear implants and, consequently, facilitate the perceptual improvements following the implantation procedure. 


\section{References}

Aghajanian, G.K., \& Marek, G.J. (1997). Serotonin induces excitatory postsynaptic potentials in apical dendrites of neocortical pyramidal cells. Neuropharmacology, 36, 589-599.

Ahveninen, J, Jaaskelainen, IP, Pennanen, S, Liesivuori, J, Ilmoniemi, RJ. \& Kahkonen, S. (2003). Auditory selective attention modulated by tryptophan depletion in humans. Neurosci Lett, 340, 181-184.

Andersen, P., Morris, R., Amaral, D., Bliss, T., \& O’Keefe, J. (2007). Historical Perspective: proposed functions, biological characteristics, and neurobiological models of the hippocampus, in: Andersen, P. (Eds.), The Hippocampus Book. Oxford University Press, USA, 27-30.

Araneda, R. \& Andrade, R. (1991). 5-Hydroxytryptamine2 and 5-hydroxytryptamine 1A receptors mediate opposing responses on membrane excitability in rat association cortex. Neuroscience, 40, 399-412.

Bard, J.A., Kucharewicz, S.A., Zgombick, J.M., Weinshank, R.L., Branchek, T.A., \& Cohen, M.L. (1996). Differences in ligand binding profiles between cloned rabbit and human 5HT(1D ) and 5-HT(1D ) receptors: ketanserin and methiothepin distinguish rabbit 5HT(1D) receptor subtypes. Naunyn-Schmiedeberg's Arch. Pharmacol., 54, 237-244.

Barnes, N.M., \& Sharp, T. (1999). The review of central 5-HT receptors and their function. Neuropharmacology, 38, 1083-1152.

Barre, A., Berthoux, C., De Bundel, D., Valjent, E., Bockaert, J., Marin, P., \& Bécamel, C. (2016). Presynaptic serotonin 2 A receptors modulate thalamocortical plasticity and associative learning. Proc. Natl. Acad. Sci. USA, 113, E1382-1391.

Basura, G.J., Abbas, A.I., O’Donohue, H., Lauder, J.M., Roth, B.L., Walker, P.D. \& Manis, P.B. 
(2008). Ontogeny of serotonin and serotonin2A receptors in rat auditory cortex. Hearing Research, 244, 45-50.

Bavelier, D., Levi, D.M., Li, R.W., Dan, Y., \& Hensch, T.K. (2010). Removing brakes on adult brain plasticity: from molecular to behavioral interventions. J. Neurosci., 30, 1496414971.

Beique, JC, Campbell, B, Perring, P, Hamblin, MW, Walker, P, Mladenovic, L \& Andrade, R. (2004). Serotonergic regulation of membrane potential in developing Rat prefrontal cortex: coordinated expression of 5-hydroxytryptamine (5-HT)1A, 5HT2A, and 5-HT7 receptors. J Neurosci, 24, 4807-4817.

Bennett, M.R. (2000) The concept of long term potentiation of transmission at Synapses. Progress in Neurobiology, 60(2), 109-137.

Bliss, T.V.P., \& Collingridge, G.L. (1993). A synaptic model of memory: long-term potentiation in the hippocampus. Nature, 361, 31-39.

Bliss, T.V.P., \& Cooke, S.F. (2011). Long-term potentiation and long-term depression: a clinical perspective. Clinics, 66(Suppl. 1), 3-17.

Bocchio, M., Fucsina, G., Oikonomidis, L., McHugh, S. B., Bannerman, D. M., Sharp, T., \& Capogna, M. (2015). Increased serotonin transporter expression reduces fear and recruitment of parvalbumin interneurons of the amygdala. Neuropsychopharmacology, 40, 3015-3026.

Bocchio, M., McHugh, S.B., Bannerman, D.M., Sharp, T., \& Capogna, M. (2016). Serotonin, amygdala and fear: assembling the puzzle. Frontiers in Neural Circuits, 10, 24.

Burnet, P.W.J., Eastwood, S.L., Lacey, K, \& Harrison, P.J. (1995). The distribution of 5-HT1A and 5-HT2A receptor mRNA in human brain. Brain Res, 676, 157-168. 
Cai, D., Chen, S., \& Glanzman, D. L. (2008). Postsynaptic Regulation of Long-Term Facilitation in Aplysia. Current Biology : CB, 18(12), 920-925.

Campbell, M.J., Lewis, D.A., Foote, S.L., \& Morrison, J.H. (1987). Distribution of choline acetyltransferase-, serotonin-, dopamine- $\beta$-hydroxylase-, tyrosine hydroxylaseimmunoreactive fibers in monkey primary auditory cortex. J. Comp. Neurol., 261, 209220.

Celada, P., Puig, M.V., \& Artigas, F. (2013). Serotonin modulation of cortical neurons and networks. Front. Integr. Neurosci., 7, 25. doi: 10.3389/fnint.2013.00025.

Chen, A., Hough, C. J., \& Li, H. (2003). Serotonin type II receptor activation facilitates synaptic plasticity via n-methyl-d-aspartate-mediated mechanism in the rat basolateral amygdala. Neuroscience, 119, 53-63.

Clemett, D.A., Punhani, T., Duxon, M.S., Blackburn, T.P., \& Fone, K.C.F. (2000). Immunohistochemical localization of the 5-HT2C receptor protein in the rat CNS. Neuropharmacology, 39, 123-132.

Cornea-Hébert, V., Riad, M., Wu, C., Singh, S.K., \& Descarries, L. (1999). Cellular and subcellular distribution of the serotonin 5-HT2A receptor in the central nervous system of adult rat. J. Comp. Neurol., 409, 187-209.

Corradetti, R., Ballerini, L., Pugliese, A.M. \& Pepeu, G. (1992). Serotonin blocks the long term potentiation induced by primed burst stimulation in the CA1 region of rat hippocampal slices. Neuroscience, 46(3), 551-8.

Cynader, M., Timney, B.N. \& Mitchell, D.E. (1980). Period of susceptibility of kitten visual cortex to the effects of monocular deprivation extends beyond six months of age. Brain Res., 191, 545-550. 
Dahlstrom, A. and Fuxe, K. (1964). Localization of monoamines in the lower brain stem. Experientia, 20(7), 398-399.

Davies, M.F., Deisz, R.A., Prince, D.A., \& Peroutka, S.J. (1987). Two distinct effects of 5hydroxytryptamine in single cortical neurons. Brain Res., 423, 347-352.

Del Angel-Meza, A.R., Ramirez-Cortes, L., Adame-Gonzalez, I. G., Gonzalez Burgos, I., \& Beas-Zarate, C. (2002). Cerebral GABA release and GAD activity in protein- and Tryptophan restricted rats during development. Int. J. Dev. Neurosci., 20, 47-54.

Deneris, E.S. (2011). Molecular genetics of mouse serotonin neurons across the lifespan. Neuroscience, 197, 17-27.

Dringenberg, H.C., Day, L.R. \& Choi, D.H. (2014). Chronic fluoxetine treatment suppresses plasticity (Long-Term Potentiation) in the mature rodent primary auditory cortex in vivo. Neural Plasticity, 571285, doi: 10.1155/2014/571285.

Dringenberg, H.C., \& Kuo, M.-C. (2006). Cholinergic, histaminergic, and noradrenergic regulation of LTP stability and induction threshold: cognitive implications. Experientia, $98,165-183$.

Edagawa, Y., Saito, H., \& Abe, K. (1998). 5-HT1A receptor-mediated inhibition of long-term potentiation in rat visual cortex. Eur. J. Pharmacol., 349, 221-224.

Edagawa, Y., Saito, H. \& Abe, Kazuho, (2000). The serotonin 5-HT2 receptor phospholipase C system inhibits the induction of long-term potentiation in the rat visual cortex. European Journal of Neuroscience, 12, 1391-1396.

Fallon, J. B., Irvine, D. R. F., \& Shepherd, R. K. (2002). Cochlear Implants and Brain Plasticity. British Medical Bulletin, 63, 183-193. 
Farber, L, Haus, U, Spath, M, \& Drechsler, S. (2004). Physiology and pathophysiology of the 5HT3 receptor. Scand J Rheumatol Suppl, 119, 2-8.

Feldman,D.E.(2009).Synaptic mechanisms for plasticity in neocortex. Annu.Rev. Neurosci., 32, $33-55$.

Forster, E.A., Cliffe, I.A., Bill, D.J., Dover, G.M., Jones, D., Reilly, Y., \& Fletcher, A. (1995). A Pharmacological profile of the selective silent 5-HT1A receptor antagonist,WAY 100635. Eur. J. Pharmacol., 281, 81-88.

Gagolewicz, P.J., \& Dringenberg, H.C. (2016). Age-Dependent Switch of the Role of Serotonergic 5-HT1A Receptors in Gating Long-Term Potentiation in Rat Visual Cortex In Vivo. Neural Plasticity, 6404082, 11 pages. doi:10.1155/2016/6404082.

García-Oscos, F., Torres-Ramírez, O., Dinh, L., Galindo-Charles, L., Pérez Padilla, E.A., Pineda, J.C., Atzori, M., \& Salgado, H. (2015). Activation of 5-HT receptors inhibits GABAergic transmission by pre-and post-synaptic mechanisms in layer II/III of the juvenile rat auditory cortex. Synapse, 69, 115-127.

Greenwood, B. N., Strong, P. V., Loughridge, A. B., Day, H. E. W., Clark, P. J., Mika, A., et al. (2012). 5-HT2C receptors in the basolateral amygdala and dorsal striatum are a novel target for the anxiolytic and antidepressant effects of exercise. PLoSOne, 7, e46118. doi:10.1371/journal.pone.0046118.

Grunschlag, CR, Haas, HL. \& Stevens, DR. (1997). 5-HT inhibits lateral entorhinal Cortical neurons of the rat in vitro by activation of potassium channel-coupled 5 HT1A receptors. Brain Res, 77, 10-17.

$\mathrm{Gu}, \mathrm{Q}$. (2002). Neuromodulatory transmitter systems in the cortex and their role in cortical plasticity. Neuroscience, 111, 815-835. 
Guiard, B. P., \& Giovanni, G. D. (2015). Central serotonin-2A (5-HT2A) receptor dysfunction in depression and epilepsy: the missing link? Frontiers in Pharmacology, 6, 46.

Gulyás, A.I., Acsády, L., \& Freund, T.F. (1999). Structural basis of the cholinergic and serotonergic modulation of GABAergic neurons in the hippocampus. Neurochemistry International, 34, 359-372.

Hamada S., Senzaki K., Hamaguchi-Hamada, K., Tabuchi, K., Yamamoto, H., Yamamoto, T., Yoshikawa, S., Okano, H., \&, Okado, N. (1998). Localization of 5-HT2A receptor in rat cerebral cortex and olfactory system revealed by immunohistochemistry using two antibodies raised in rabbit and chicken. Mol. Brain Res., 54, 199-211.

Harding, A., \& Paxinos, G. (2004). The serotonin and tachykinin systems, in: Paxinos, G. (Ed.), The Rat Nervous System, 3rd ed. Elsevier Academic Press, San Diego, pp. 1205-1256.

Hasselmo, M.E. (1995). Neuromodulation and cortical function: modeling the physiological basis of behavior. Behavioural Brain Research, 67, 1-27.

Hebb, D.O. (2002). The Organization of Behavior. Lawrence Erlbaum Associates, Mahwah, New Jersey.

Hegerl, U. \& Juckel, G. (1993). Intensity dependence of auditory evoked potentials as an indicator of central serotonergic neurotransmission: a new hypothesis. Biol Psychiatry, 33, 173-187.

Hogsden, J.L., \& Dringenberg, H.C. (2009a). Decline of long-term potentiation (LTP) in the rat auditory cortex in vivo during postnatal life: Involvement of NR2B units. Brain Research, 1283, 25-33.

Hogsden, J.L., \& Dringenberg, H.C. (2009b). NR2B subunit-dependent long-term potentiation 
enhancement in the rat cortical auditory system in vivo following masking of patterned auditory input by white noise exposure during early postnatal life. Eur. J. Neurosci., 30, 376-384.

Hogsden, J.L., Rosen, L.G., \& Dringenberg, H.C. (2011). Pharmacological and deprivation induced reinstatement of juvenile-like long-term potentiation in the primary auditory cortex of adult rats. Neuroscience, 186, 208-219.

Hoyer, D., Clarke, D.E., Fozard, J.R., Hartig, P.R., Martin, G.R., Mylecharane, E.J., Saxena, P.R., \& Humphrey, P.P. (1994). International Union of Pharmacology classification of receptors for 5-hydroxytryptamine (serotonin). Pharmacol. Rev., 46, 157-203.

Hurley, LM, Thompson, AM. \& Pollak, GD. (2002) Serotonin in the inferior colliculus. Hear Res, 168, 1-11.

Inaba, M., Maruyama, T., Yoshimura, Y., Hosoi, H. \& Komatsu, Y. (2009). Facilitation of low frequency stimulation-induced long-term potentiation by endogenous noradrenaline and serotonin in developing rat visual cortex. Neuroscience Research, 64(2), 191-198.

Jakab, R.L., \& Goldman-Rakic, P.E. (2000). Segregation of serotonin 5-HT2A and 5-HT3 receptors in inhibitory circuits of the primate cerebral cortex. J. Comp. Neurol., 417, 337 348.

Ji, W. \& Suga, N. (2007). Serotonergic modulation of plasticity of the auditory cortex elicited by fear conditioning. Journal of Neuroscience, 27(18), 4910-4918.

Kahkonen, S, Ahveninen, J, Pennanen, S, Liesivuori, J, Ilmoniemi, RJ. \& Jaaskelainen, IP. (2002a). Serotonin modulates early cortical auditory processing in healthy subjects: evidence from MEG with acute tryptophan depletion. Neuropsychopharmacology, 27, 862-868. 
Kahkonen, S, Jaaskelainen, IP, Pennanen, S, Liesivuori, J. \& Ahveninen, J. (2002b). Acute tryptophan depletion decreases intensity dependence of auditory evoked magnetic N1/P2 dipole source activity. Psychopharmacology (Berl), 164, 221-227.

Kaur, S., Rose, H.J., Lazar, R., Liang, K., \& Metherate, R. (2005). Spectral integration in primary auditory cortex: laminar processing of afferent input, in vivo and in vitro. Neuroscience, 134(3), 1033-1045.

Kilpatrick, G.J., Jones, B.J., \& Tyers, M.B., (1987). Identification and distribution of 5-HT3 receptors in rat brain using radioligand binding. Nature, 330, 746-748.

Kim, H.S., Jang, H.J., Cho, K.H., Hahn, S.J., Kim, M.J., Yoon, S.H., Jo, Y.H., Kim, M.S. \& Rhie, D.J.(2006). Serotonin inhibits the induction of NMDA receptor-dependent Long term potentiation in the rat primary visual cortex. Brain Research, 1103(1), 49-55.

Kim, J., Jung, S.Y., Lee, Y.K., Park, S., Choi, J.S., Lee, C.J., Kim, H.S., Choi, Y.B., Scheiffele, P., Bailey, C.H. Kandel, E.R. \& Kim, J.H. (2008). Neuroligin-1 is required for normal expression of LTP and associative fear memory in the amygdala of adult animals. Proc. Natl. Acad. Sci. USA., 105, 9087-9092.

Kojic, L., Dyck, R.H., Gu, Q., Douglas, R.M., Matsubara, J., \& Cynader, M.S. (2000) Columnar distribution of serotonin-dependent plasticity within kitten striate Cortex. Proceedings of the National Academy of Science, USA, 97(4), 1841-1844.

Kojic, L., Gu, Q., Douglas, R.M., \& Cynader, M.S. (1997). Serotonin facilitates synaptic plasticity in kitten visual cortex: an in vitro study. Brain Research, Developmental Brain Research, 101(1-2), 299-304.

Kojic, L., Gu, Q., Douglas, R. M., \& Cynader, M. S. (2001). Laminar distribution of Cholinergic and serotonergic-dependent plasticity within kitten visual cortex. Brain Res. Dev. Brain Res., 126, 157-162. 
Kojima, T, Matsumoto, M, Togashi, H, Tachibana, K, Kemmotsu, O, \& Yoshioka, M. (2003). Fluvoxamine suppresses the long-term potentiation in the hippocampal CA1 field of anesthetized rats: an effect mediated via 5-HT1A receptors. Brain Res, 959, 165-168.

Lagerlund, T.D. (2002). Volume conduction, in: Daube, J.R. (Eds.), Clinical Neurophysiology. Oxford University Press, USA, 28-30.

Lakoski, J.M., \& Aghajanian, G.K. (1985). Effects of ketanserin in neuronal responses to serotonin in the prefrontal cortex, lateral geniculate and dorsal raphe nucleus. Neuropharmacology, 24, 265-273.

Lambe, EK, Goldman-Rakic, PS. \& Aghajanian, GK. (2000). Serotonin induces EPSCs preferentially in layer V pyramidal neurons of the frontal cortex in the rat. Cereb Cortex, $10,974-980$.

Lanzenberger, R. R., Mitterhauser, M., Spindelegger, C., Wadsak, W., Klein, N., Mien, L.-K., Holik, A, Attarbaschi, T, Mossaheb, N, Sacher, J, Geiss-Granadia, T, Kletter, K, Kasper, S, \& Tauscher, J. (2007). Reduced serotonin-1A receptor binding in social anxiety disorder. Biol.Psychiatry, 61,1081-1089.

Lesch, K \& Waider, J. (2012). Serotonin in the modulation of neural plasticity and networks: implications for neurodevelopmental disorders. Neuron, 76, 175-191.

Leysen, J.E., Niemegeers, C.J.E., Van Nueten, J.M., \& Laduron, P.M. (1982). [ ${ }^{3}$ H]ketanserin (R 41 468), a selective ${ }^{3} \mathrm{H}$-ligand for serotonin 2 receptor bidning sites. Mol. Pharmacol., 21 , 301-314.

Lummis, SC. (2004). The transmembrane domain of the 5-HT3 receptors: its role in selectivity and gating. Biochem Soc Trans, 32(3), 535-539.

Lynch, M.A. (2004). Long-term potentiation and memory. Physiol. Rev., 84, 87-136. 
Malenka, R.C., \& Bear, M.F. (2004). LTP and LTD: an embarrassment of riches. Neuron, 44, 5 21.

Malgouris, C., Flamand, F., \& Doble, A. (1993). Autoradiographic studies of RP 62203, a potent $5-\mathrm{HT}_{2}$ receptor antagonist. Pharmacological characterization of $\left[{ }^{3} \mathrm{H}\right] \mathrm{RP} 62203$ binding in the rat brain. Eur. J. Pharmacol., 233, 37-45.

Martin, S.J., \& Morris, R.G.M. (2002). New life in an old idea: the synaptic plasticity and memory hypothesis revisited. Hippocampus, 12, 609-636.

Massey, P.V. \& Bashir, Z.I. (2007). Long-term depression: multiple forms and implications for brain function. Trends Neurosci. 30, 176-184.

Maya Vetencourt, J.F., Sale, A., Viegi, A., Baroncelli, L., De Pasquale, R., O’Leary, O.F., Castrén, E., \& Maffei, L. (2008). The antidepressant fluoxetine restores plasticity in the adult visual cortex. Science, 320, 385-388.

Meunier, C. N. J., Amar, M., Lanfumey, L., Hamon, M., and Fossier, P. (2013). 5-HT1A receptors direct the orientation of plasticity in layer 5 pyramidal neurons of the mouse prefrontal cortex. Neuropharmacology, 71, 37-45.

Meunier, C. N., Callebert, J., Cancela, J-M., and Fossier, P. (2015). Effect of dopaminergic D1 receptors on plasticity is dependent of serotoninergic 5-HT1AreceptorsinL5-pyramidal neurons of the prefrontal cortex. PLoSOne, 10, e0120286. doi:10.1371/journal.pone.0120286

Meunier, C. N., Cancela, J. M., and Fossier, P. (2017). Lack of GSK3 $\beta$ activation and modulation of synaptic plasticity by dopamine in 5-HT1A-receptor KO mice. Neuropharmacology, 113, 124-136. 
Meunier, C.N.J., Chameau, P., \& Fossier, P.M. (2017). Modulation of synaptic plasticity in the cortex needs to understand all the players. Frontiers in Synaptic Neuroscience, 9, 2.

Maren, S. (2005). Synaptic mechanisms of associative memory in the amygdala. Neuron., 47, 783-786.

Morales, M, Battenberg, E, de Lecea, L, \& Bloom, FE. (1996). The type 3 serotonin receptor is expressed in a subpopulation of GABAergic neurons in the rat neocortex and hippocampus. Brain Res, 731, 199-202.

Moreau, A. W., Amar, M., Le Roux, N., Morel, N., \& Fossier, P. (2010). Serotoninergic fine tuning of the excitation-inhibition balance in rat visual cortical networks. Cereb. Cortex, $20,456-467$.

Neves, G., Cooke, S.F., \& Bliss, T.V.P. (2008). Synaptic plasticity, memory and the hippocampus: a neural network approach to causality. Nat. Rev. Neurosci. 9, 65-75. Newberry, N.R., Footitt, D.R., Papanastassiou, V., \& Reynolds, D.J.M. (1999). Actions of 5-HT on human neocortical neurons in vitro. Brain Res., 833, 93-100.

Nichols, D.E. \& Nichols, C.D. (2008). Serotonin receptors. Chem. Rev., 108, 1614-1641.

Normann, C, Peckys, D, Schulze, CH, Walden, J, Jonas, P, \& Bischofberger, J (2000). Associative long-term depression in the hippocampus is dependent on postsynaptic $\mathrm{N}$ type Ca2p channels. J Neurosci, 20, 8290-8297.

Ohashi, S, Matsumoto, M, Togashi, H, Ueno, K, \& Yoshioka, M (2003). The serotonergic modulation of synaptic plasticity in the rat hippocampo-medial prefrontal cortex pathway. Neurosci Lett, 342, 179-182.

Park, S.-W., Jang, H. -J., Cho, K.-H., Kim, M.-J., Yoon, S.H. \& Rhie, D.-J. (2012).

Developmental switch of the serotonergic role in the induction of synaptic long-term 
potentiation in the rat visual cortex. Korean Journal of Physiology and Pharmacology, $16(1), 65-70$.

Passani, M.B., Pugliese, A.M., Azzurrini, M. \& Corradetti, R. (1994). Effects of DAU6215, a novel 5-hydroxytryptamine3 (5-HT3) antagonist on electrophysiological properties of the rat hippocampus. Br. J. Pharmacol., 112, 695-703.

Paxinos, G., \& Watson, C. (2007). The Rat Brain In Stereotaxic Coordinates. $6^{\text {th }}$ Edition. Elsevier Inc. Academic Press.

Peroutka, S.J., 1990. 5-hudrosytryptamine receptor subtypes. Pharmacol. Toxicol., 67, 373-383.

Persico, A.M., Mengual, E., Moessner, R., Hall, F.S., Revay, R.S., Sora, I., Arellano, J., DeFelipe, J., Gimenez-Amaya, J.M., Conciatori, M., Marino, R., Baldi, A., Cabib, S., Pascucci, T., Uhl, G.R., Murphy, D.L., Lesch, K.P., Keller, F. \& Hall, S.F. (2001). Barrel pattern formation requires serotonin uptake by thalamocortical afferents, and not vesicular monoamine release. J. Neurosci., 21, 6862-6873.

Piguet, P, \& Galvan, M (1994). Transient and long-lasting actions of 5-HT on rat dentate gyrus neurones in vitro. J Physiol, 481, 629-639.

Plosker, G.L., \& Goa, K.L. (1991). Granisetron. A review of its pharmacological properties and therapeutic use as an antiemetic. Drugs, 42, 805-824.

Power, A.E. (2004). Slow-wave sleep, acetylcholine, and memory consolidation. Proc. Natl. Acad. Sci. U.S.A., 101, 1795-1796.

Puig, MV, Santana, N, Celada, P, Mengod, G. \& Artigas, F. (2004). In vivo excitation of GABA interneurons in the medial prefrontal cortex through 5-HT3 receptors. Cereb Cortex, $14,1365-1375$. 
Puig, M. V., \& Gulledge, A. T. (2011). Serotonin and prefrontal cortex function: neurons, networks, and circuits. Mol. Neurobiol., 44, 449-464.

Rao, D. (2012). Neuromodulation of intrinsic and synaptic plasticity in auditory cortex (Dissertation). Retrieved from ProQuest Dissertations and Theses. (UMI Number: 3495527).

Reznic, J. \& Staubli, U. (1997). Effects of 5-HT3 receptor antagonism on hippocampal Cellular activity in the freely moving rat. Journal of Neurophysiology, 77(1), 517-521.

Rozas, C, Loyola, S., Ugarte, G., Zeise, M.L., Reyes-Parada, M, Pancetti, F., Rojas, P., \& Morales, B. (2012). Acutely applied MDMA enhances long-term potentiation in rat hippocampus involving D1/D5 and 5-HT2 receptors through a polysynaptic mechanism. European Neuropsycholpharmacology, 22, 584-595.

Ruiz-Perera, L., Muniz, M., Vierci, G., Bornia, N., Baroncelli, L., Sale, A., \& Rossi, F.M. (2015). Fluoxetine increases plasticity and modulates the proteomic profile in the adult visual. Cortex. Sci. Rep., 5:12517. doi: 10.1038/srep12517.

Rumpel, S., LeDoux, J., Zador, A., \& Malinow, R. (2005). Postsynaptic receptor trafficking underlying a form of associative learning. Science., 308, 83-88.

Saha, S., Gamboa-Esteves, F. O., \& Batten, T. F. C. (2010). Differential distribution of 5-HT 1A and 5-HT 1B-like immunoreactivities in rat central nucleus of the amygdala neurones projecting to the caudal dorsomedial medulla oblongata. Brain Res., 1330, 20-30.

Sanger, G.J., \& Nelson, D.R. (1989). Selective and functional 5-hydroxytryptamine 3 receptor antagonism by BRL 43694 (granisetron). Eur. J. Pharmacol., 159, 113-124.

Santana, N., Bortolozzi, A., Serrats, J., Mengod, G., and Artigas, F. (2004). Expression of serotonin1A and serotonin2A receptors in pyramidal and GABAergic neurons of the rat 
prefrontal cortex. Cereb. Cortex, 14, 1100-1109.

Scammell, T.E., Arrigoni, E., \& Lipton, J.O. (2017). Neural circuitry of wakefulness and sleep. Neuron, 93, 747-765.

Sodhi, M.S.K. \& Sanders-Bush, E. (2004). Serotonin and brain development. International Review of Neurobiology, 59, 111-74.

Soutar, C.N., Rosen, L.G., Rodier, S.G., \& Dringenberg, H.C. (2016). Effects of patterned sound deprivation on short- and long-term plasticity in the rat thalamocortical auditory system in vivo. Neural Plasticity 2016, Article ID 3407135, 10 pages.

Speechley, W.J., Hogsden, J.L., \& Dringenberg, H.C. (2007). Continuous white noise exposure during and after auditory critical period differentially alters bi-directional thalamocortical plasticity in rat auditory cortex in vivo. Eur. J. Neurosci., 26, 2576-2584.

Staubli, U, \& Xu FB (1995). Effects of 5-HT3 receptor antagonism on hippocampal theta rhythm, memory, and LTP induction in the freely moving rat. J Neurosci, 15, 2445.

Törk, I. (1990). Anatomy of the serotonergic system. Ann. N.Y. Acad. Sci., 600, 9-35.

Tsumoto, T. (1992). Long-term potentiation and long-term depression in the neocortex. Progr. Neurobiol., 39, 209-228.

Tzounopoulos, T., Ricardo, M., \& Leão, R.M., (2012). Mechanisms of memory and learning in the auditory system, in: Trussell, L.O., Popper, A.N., Fay, L.O. (Eds.), Synaptic Mechanisms in the Auditory System. Springer Handbook of Auditory Research, Springer, New York, 203-226.

Vanderwolf, C.H. (1990). An introduction to the electrical activity of the cerebral cortex: relations to behavior and control by subcortical inputs, in: Kolb, B., \& Tees, R.C. (Eds.), 
The Cerebral Cortex of the Rat. Cambridge, MA: MIT Press, 151-189.

Villani, F. \& Johnston, D. (1993). Serotonin inhibits induction of long-term potentiation at commissural synapses in hippocampus. Brain Research, 606(2), 304-308.

Walstab, J, Rappold, G, \& Niesler, B. (2010). 5-HT3 receptors: role in disease and target of drugs. Pharmacol Ther, 128, 146-169.

Wang, RY, \& Arvanov, VL (1998). M100907, a highly selective 5-HT2A receptor antagonist and a potential atypical antipsychotic drug, facilitates induction of long-term potentiation in area CA1 of the rat hippocampal slice. Brain Res, 779, 309-313.

Wyss, J.M., Swanson, L.W., \& Cowan, W.M. (1979). A study of subcortical afferents to the hippocampal formation in the rat. Neuroscience, 4, 463-476.

Yamamoto, R., Hatano, N., Sugai, T., \& Kato, N. (2014). Serotonin induces depolarization in lateral amygdala neurons by activation of TRPC-like current and inhibition of GIRK current depending on 5-HT2C receptor. Neuropharmacology, 82C, 49-58. 